\title{
Statins are potential anticancerous agents (Review)
}

\author{
ABDULLAH K. ALTWAIRGI \\ Comprehensive Cancer Center, King Fahad Medical City, Riyadh, Saudi Arabia
}

Received September 17, 2014; Accepted December 23, 2014

DOI: 10.3892/or.2015.3741

\begin{abstract}
Statins are inhibitors of 3-hydroxy-3-methylglutarylcoenzyme A reductase (HMGCR), which is a rate-limiting enzyme in the mevalonate pathway. The pleiotropic effects of statins may be mediated by the inhibition of downstream products such as small GTP-binding proteins, Rho, Ras and Rac whose localization and function are dependent on isoprenylation. Preclinical studies of statins in different cancer cell lines and animal models showed antiproliferative, pro-apoptotic and anti-invasive effects. Notably, statins showed targeted action in cancerous cell lines compared to normal cells. Previous studies have also shown the synergistic effects of statins with chemotherapeutic agents and radiotherapy. This effect of statins was also observed in chemotherapeutic-resistant tumors. Statins were reported to sensitize the cells to radiation by arresting them in the late G1 phase of the cell cycle. Similarly, population-based studies also demonstrated a chemopreventive and survival benefit of statins in various types of cancers. However, this benefit has yet to be proven in clinical trials. The interindividual variation in response to statins may be contributed to many genetic and non-genetic factors, including single-nucleotide polymorphisms in $H M G C R$ gene and the overexpression of heterogeneous nuclear ribonucleoprotein A1, which was reported to reduce HMGCR enzyme activity. However, more studies with large phase III randomized controlled trials in cancer patients should be conducted to establish the effect of statins in cancer prevention and treatment.
\end{abstract}

\section{Contents}

1. Introduction

2. Mechanism of action of statins

3. Antitumor effects of statins in preclinical studies

4. Antitumor effects of statins in clinical studies

5. Synergism of statins with radiotherapy and chemotherapy

6. Conclusion

Correspondence to: Dr Abdullah K. Altwairgi, Comprehensive Cancer Center, King Fahad Medical City, 59046 Dabab Street, Sulemania, Riyadh 11525, Saudi Arabia

E-mail: drtwairqi@hotmail.com; aaltwairqi@kfmc.med.sa

Key words: cancer, clinical studies, preclinical studies, populationbased studies, statins

\section{Introduction}

The global burden due to cancer increased to 14.1 million new cases and 8.2 million cancer-associated mortalities in 2012 (1). The outcome of cancer patients remains poor, despite recent advances in the understanding of the molecular mechanism of tumorigenesis. Thus, more effective initial treatments for this intractable disease are required. Recent therapies under investigation include immunotherapy, chemotherapy, targeted molecular, antiangiogenic and gene therapy, radiation enhancement and drugs for overcoming resistance (2). Statins are inhibitors of 3-hydroxy-3-methyl-glutaryl-coenzyme A reductase (HMGCR), commonly used as cholesterol-lowering agents (3), that have proven their effectiveness in the treatment of cardiovascular diseases. Preclinical evidence has indicated their antiproliferative, pro-apoptotic, anti-invasive and radiosensitizing properties (4), and there are emerging interests in the use of statins as anticancer agents. In the present study, we reviewed the current data of statins in cancer.

\section{Mechanism of action of statins}

Inhibition of HMGCR by statins is a rate-limiting step in the mevalonate pathway. The products of the mevalonate pathway include isoprene units incorporated into sterol and non-sterol compounds. This inhibition by a statin may result in decreased levels of mevalonate and its downstream products, which affects critical cell functions such as membrane integrity, cell signaling, protein synthesis and cell cycle progression. The effect of statins on these processes and consequently on tumor cells, may therefore be able to control tumor initiation, growth and metastasis (Fig. 1) (5-17).

\section{Antitumor effects of statins in preclinical studies}

The in vitro preclinical studies in different cell lines have shown the ability of statins to suppress tumor growth and development. Statins exert antiproliferative, pro-apoptotic and anti-invasive effects in different cancer cell lines with varying sensitivity. The antimyeloma activity of statins in humans was first reported with the concomitant simvastatin administration in refractory multiple myeloma (MM), which showed reduced drug resistance (18). However, high-dose simvastatin treatment $(15 \mathrm{mg} / \mathrm{kg} / \mathrm{day})$ in heavily pretreated MM patients transiently increased osteoclast activity and gastrointestinal side-effects, leading to premature discontinuation (19). A pre-operative study in primary invasive breast cancer patients 


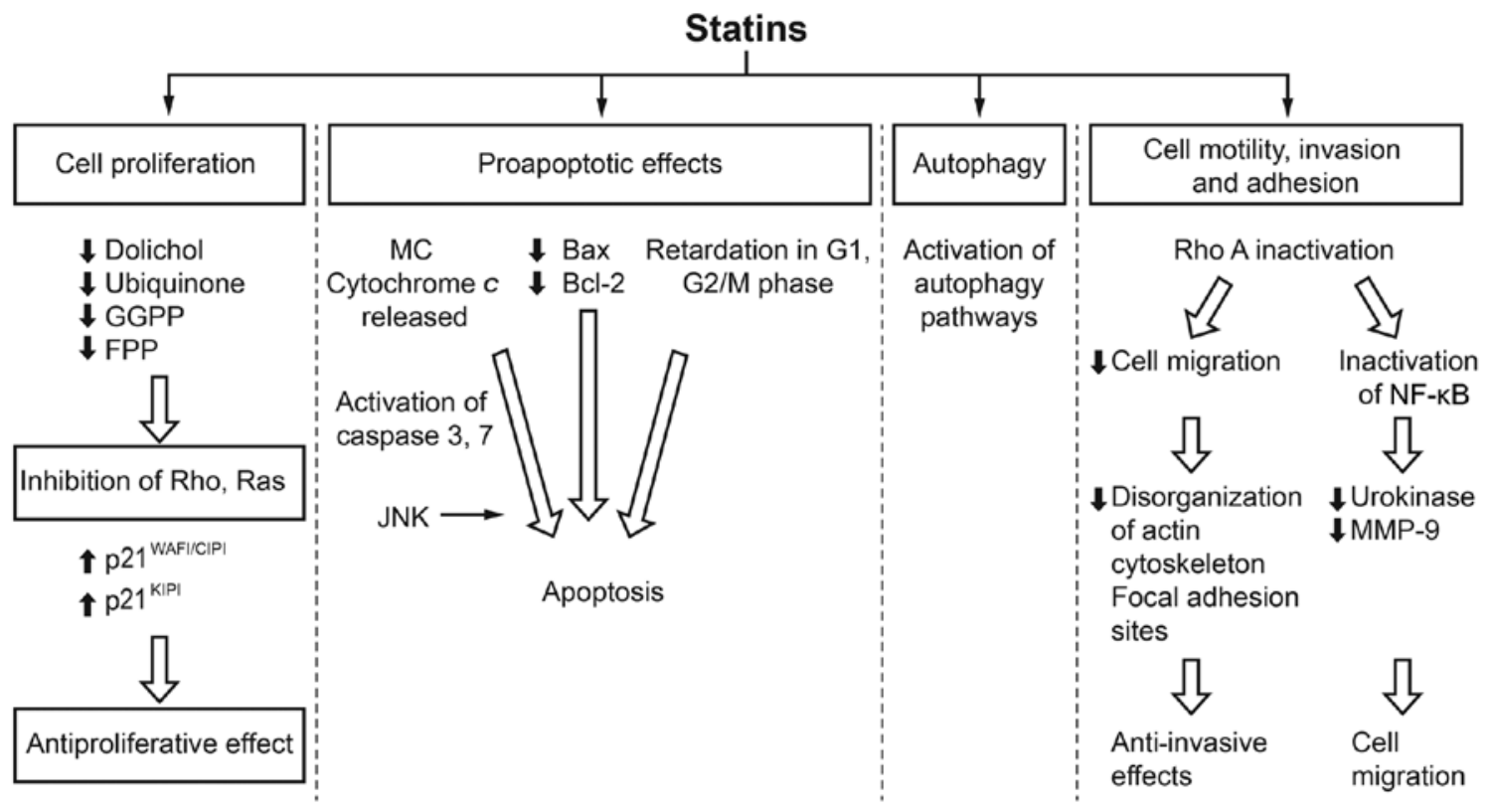

Figure 1. Pleiotropic effects of statins (5-17). Cyt, cytochrome $c$; FPP, farnesyl pyrophosphate; GGPP, geranylgeranyl pyrophosphate; p2 $1^{\mathrm{WAF} / \mathrm{CIP1}}$ and $\mathrm{p} 27^{\mathrm{KIPl}}$, two cyclin-dependent kinase inhibitors; JNK, c-jun NH2-terminal kinase; MC, mitochondria; MMP-9, matrix metalloproteinase-9; NF- $\mathrm{kB}$, nuclear factor кB.

investigated atorvastatin-induced effects on tumor proliferation and HMGCR expression while analyzing HMGCR as a predictive marker for statin response. Results of that study suggest HMGCR is targeted by statins in breast cancer cells in vivo, and that statins may have an antiproliferative effect in HMGCR-positive tumors (20). Furthermore, fluvastatin reduced tumor proliferation and increased apoptotic activity in high-grade, stage $0 / 1$ breast cancer in invasive breast cancer patients (21). Statin-induced effects and the underlined mechanism in different cancer cell lines are presented in Table I.

Besides their in vitro efficacy, statins have also been shown to have in vivo antitumor effects in various animal models of cancer. Their efficacy as chemopreventive agents has been demonstrated in radiation-induced mammary tumorigenesis (22), chemical-induced colon tumorigenesis in rodent models $(23,24)$, human myeloid leukemia and glioma cancer cells inoculated in severe combined immunodeficient mice $(25,26)$, and chemical-induced lung tumor in mice (27). Statins have also been shown to reduce metastasis in rat lymphoma (28), rat fibrosarcoma (29), mouse mammary tumor (30), murine colon tumor (31) and mouse melanoma (32). Furthermore, statins increased the in vivo antitumor effect of doxorubicin in three tumor models accompanied by attenuation of its cardiotoxicity (33). Similarly, statins increased the antitumor effect of tumor necrosis factor by inhibiting the tumor-induced angiogenesis in a murine tumor model (34). The effect of statin-induced anticancer activity in different animal models is presented in Table I.

\section{Antitumor effects of statins in clinical studies}

Observational and retrospective studies reporting cancer risk with statin usage. Accumulating evidence has focused on pre-diagnostic use of statins in reducing risk of lethal prostate cancer (35). In a prospective cohort study of 34,989 USA male health professionals, the use of statins was associated with a reduced risk of advanced prostate cancer. The risk of advanced disease was lower with longer statin use $(P$ trend $=0.003)$ vs. never use. The relative risk (RR) was 0.60 [95\% confidence interval (CI), 0.35-1.03] for $<5$ years of use and 0.26 (95\% CI, 0.08-0.83) for $\geq 5$ years of use. There was no association between statin use and risk of total prostate cancer (RR, 0.96; 95\% CI, 0.85-1.09) (36). In a Denmark-based case-control study $(\mathrm{n}=42,480)$, statin use was associated with an overall risk reduction $(6 \%)$ that was specifically higher among patients with advanced prostate cancer (10\%) (37). Similarly, a decreased risk in mortality was noted among 11,772 newly diagnosed nonmetastatic prostate cancer patients in the UK. Furthermore, decreased risks of prostate cancer mortality and all-cause mortality were reported in patients who used statins prior to diagnosis [hazard ratio (HR), 0.55, 95\% CI, 0.41-0.74; and HR, $0.66,95 \%$ CI, 0.53-0.81, respectively]. The results were higher compared to those obtained from patients who initiated the treatment only after diagnosis (HR, 0.82, 95\% CI, 0.71-0.96; and HR, 0.91, 95\% CI, 0.82-1.01, respectively) (38). In another prospective, population-based cohort study $(n=1001)$, statin use prior to prostate cancer diagnosis was unrelated to prostate cancer recurrence/progression, but was associated with a decrease in the risk of prostate cancer-specific mortality (39).

Data from observational studies have addressed the risk of glioma among statin users $(40,41)$. The use of simvastatin and lovastatin for $>6$ months was inversely associated with glioma risk (40). A recent large nationwide case-control study (41) conducted in Denmark in patients with glioma (2,656 cases and 18,480 controls) also showed a reduction in the risk of glioma among long-term statin users compared with non-users, and the risk was inversely related to the intensity of statin treatment among users [odds ratio (OR), 0.71, 95\% CI, 0.44-1.15 for highest intensity statin users]. This potential chemopreventive effect was limited to users of lipophilic statins (41).

Population-based studies have shown $19 \%$ reductions in esophageal cancer incidence where statins have been used. 


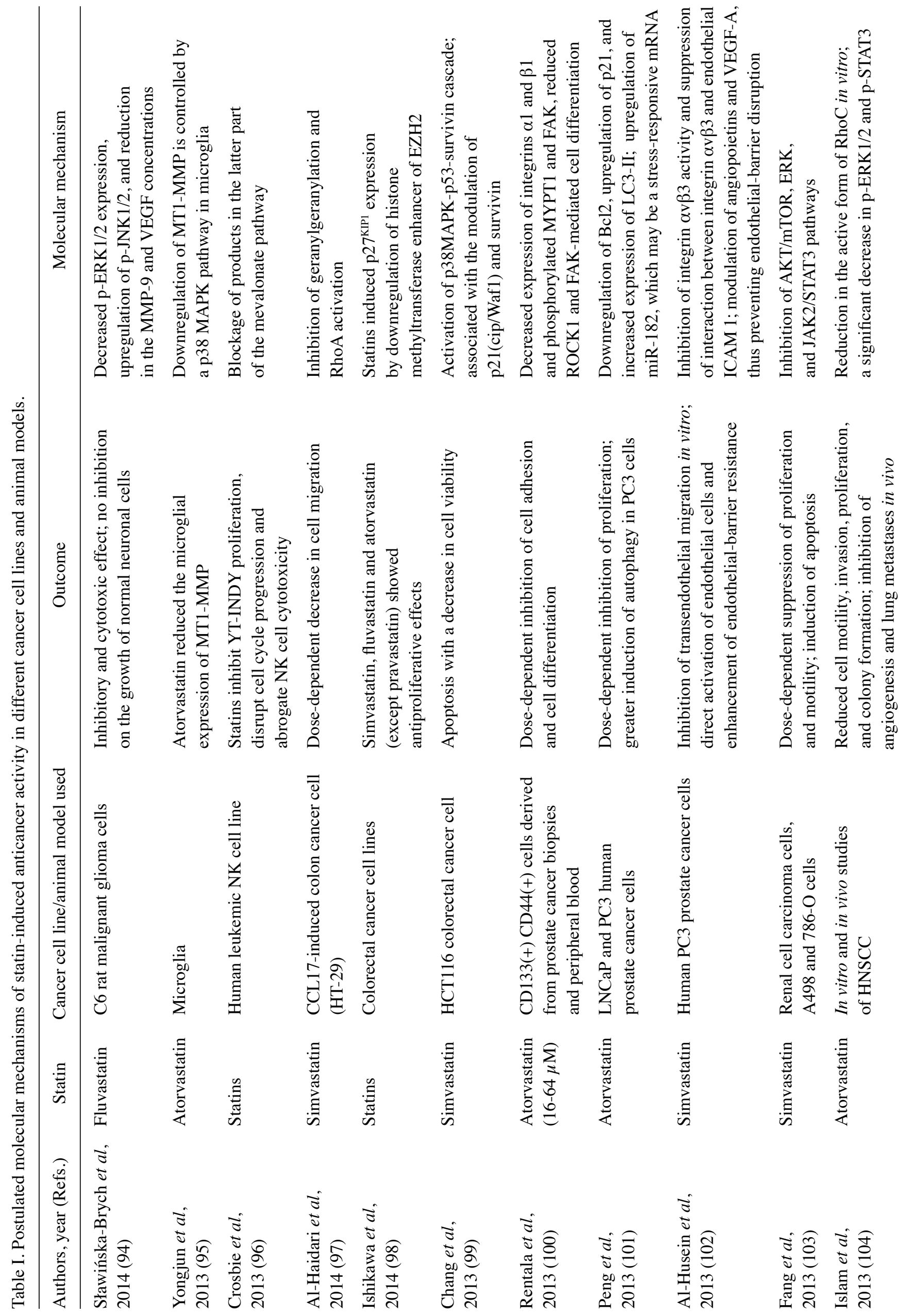




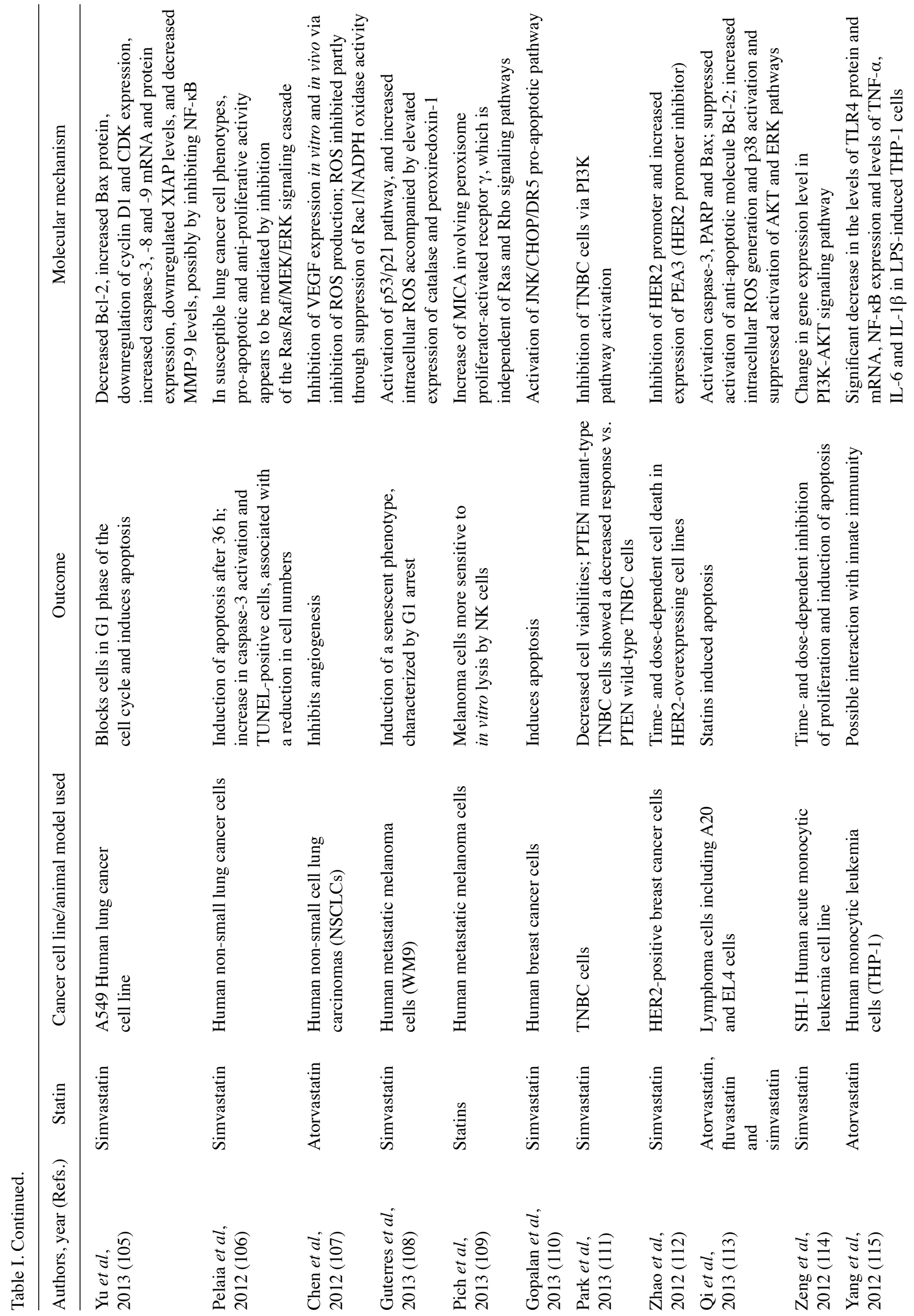




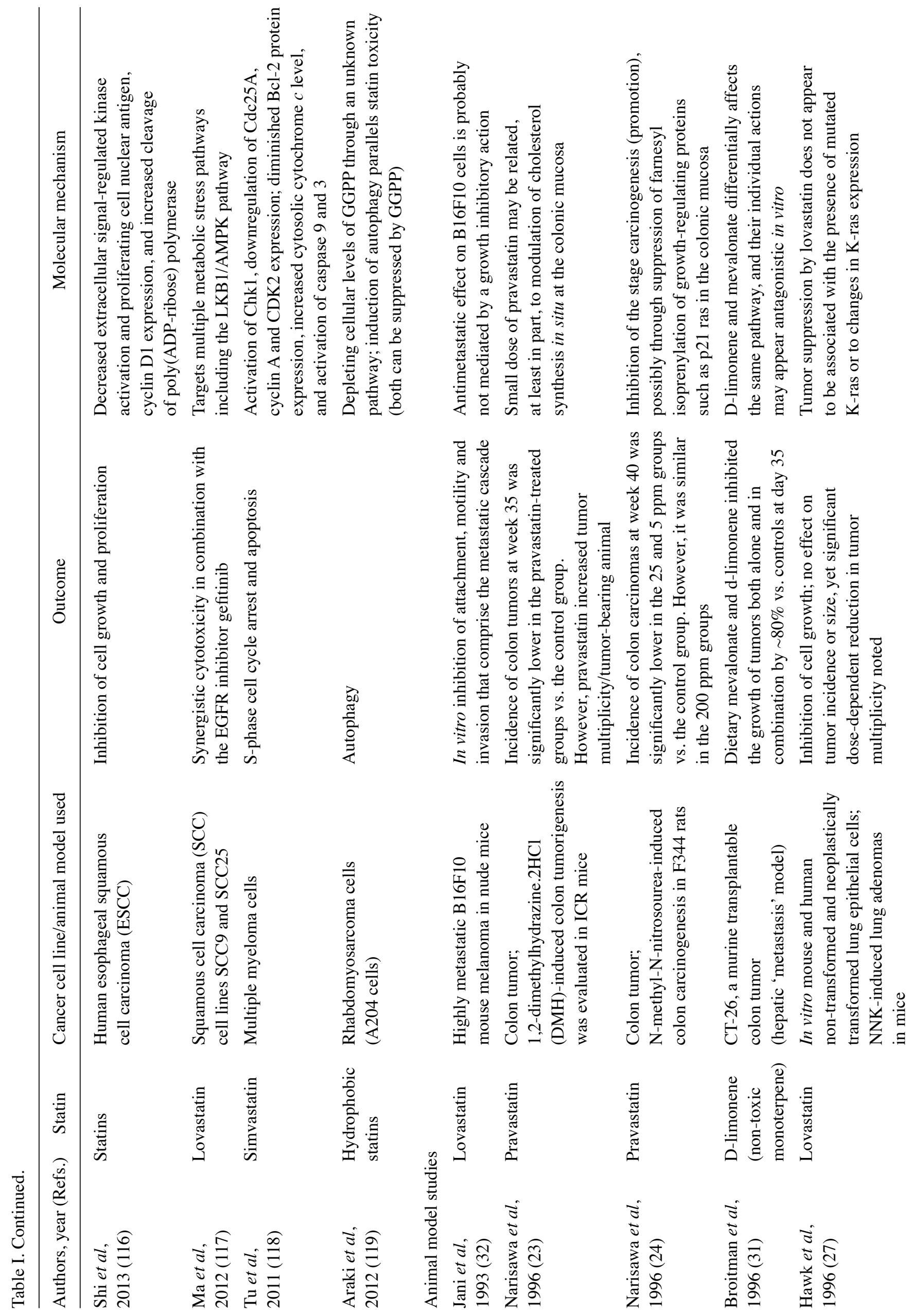




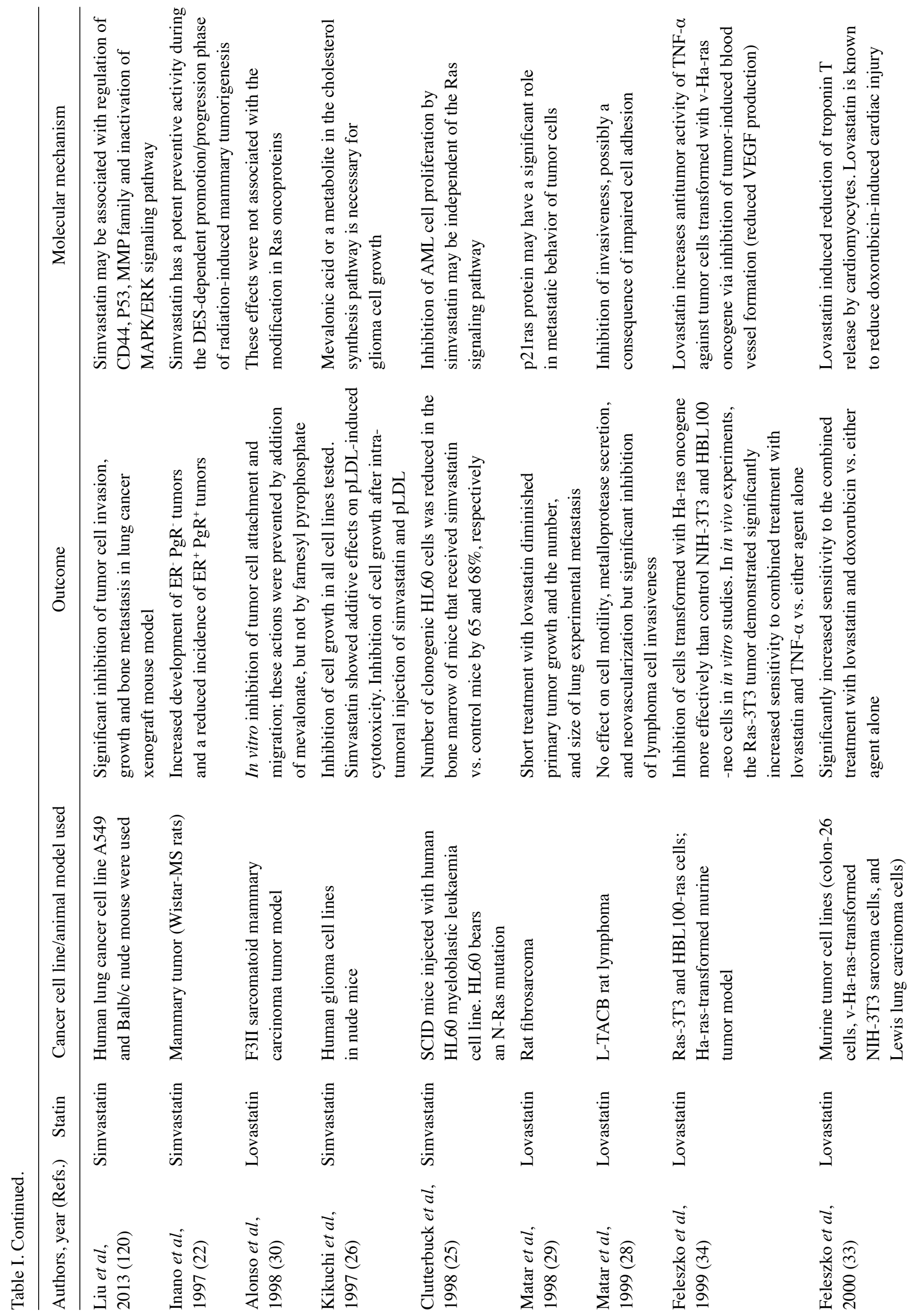




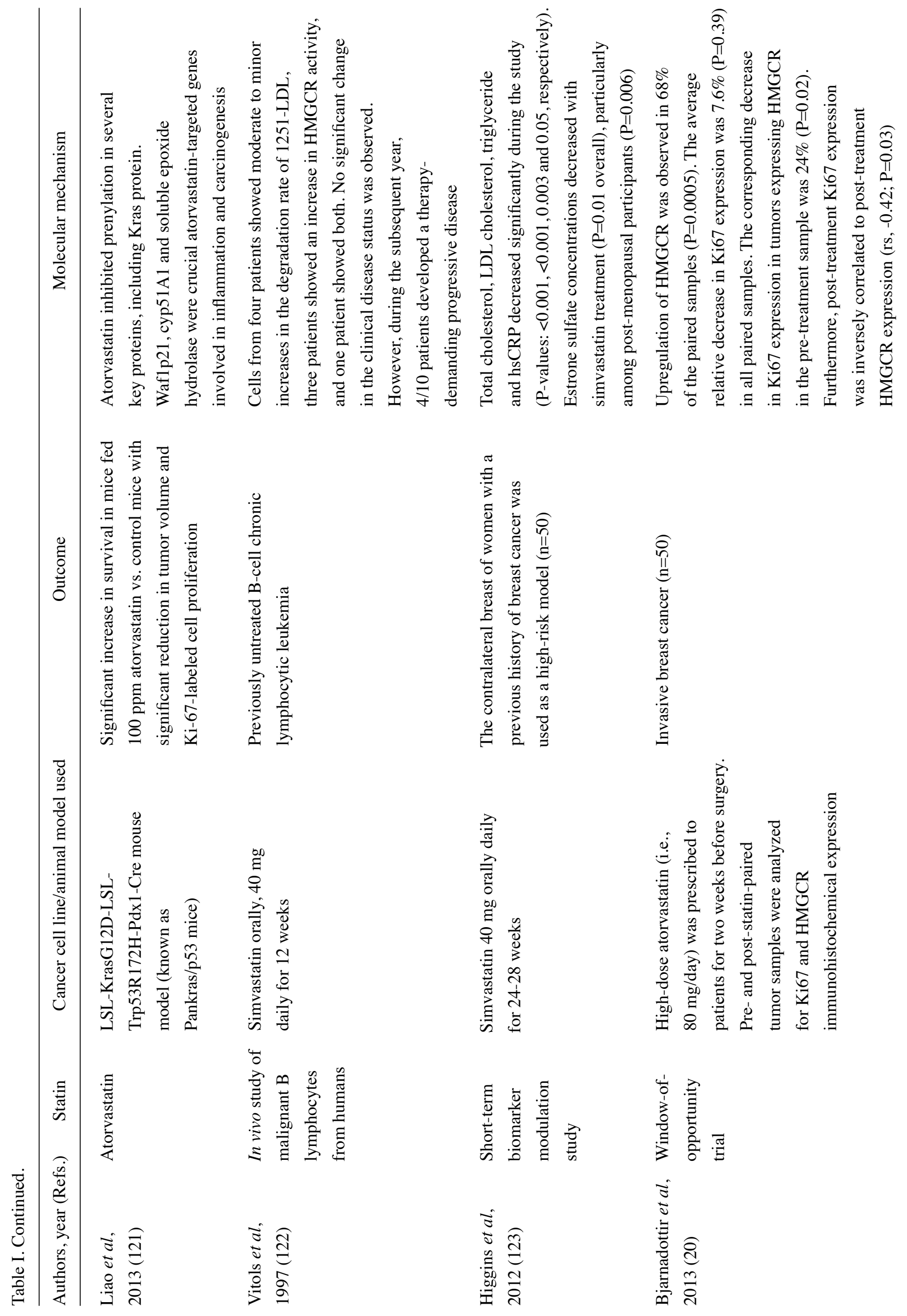




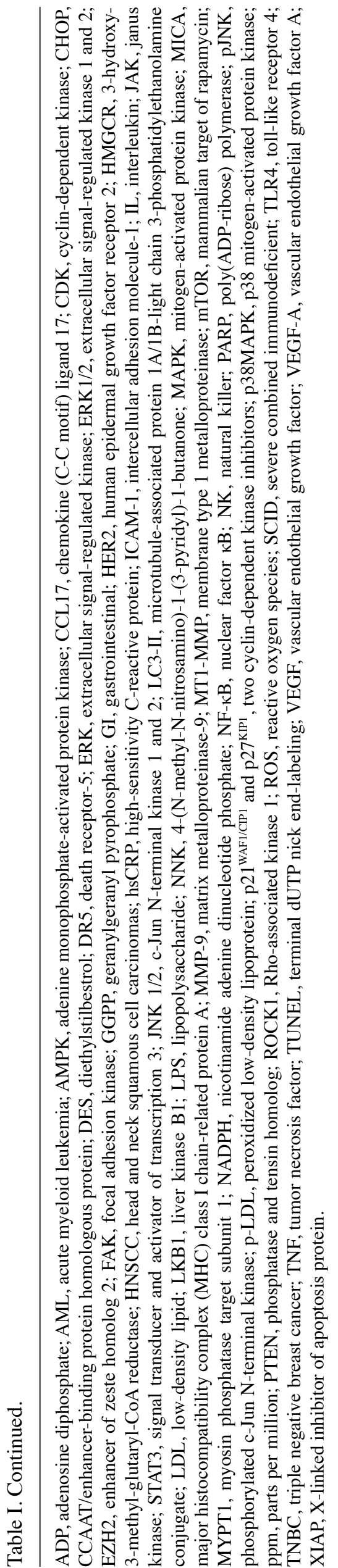

Observational studies have shown that statins reduced the incidence of adenocarcinoma in patients with Barrett's esophagus (BE) by $43 \%$; this effect was further enhanced by a $74 \%$ decrease in risk reduction in patients taking a combination of nonsteroidal anti-inflammatory drugs and statins (42).

Findings of a meta-analysis showed that statins are associated with a reduced risk of esophageal cancer, particularly in patients with BE. In a subset of patients with BE (5 studies, 312 esophageal adenocarcinomas in 2,125 patients), statins were associated with a significantly decreased risk (41\%) of esophageal adenocarcinomas after adjusting for potential confounders (adjusted OR, 0.59, 95\% CI, 0.45-0.78) (43). These findings were consistent with those of another metaanalysis of 11 observational studies. The pooled adjusted data showed statin use was associated with a lower incidence of the combined esophageal cancers (OR, 0.81, 95\% CI, 0.75-0.88). Furthermore, their chemopreventive effect was increased in combination with cyclo-oxygenase inhibitors in reducing the risk of adenocarcinoma in $\mathrm{BE}(\mathrm{OR}, 0.26,95 \% \mathrm{CI}, 0.1-0.68)$ (44).

A meta-analysis of 26 randomized controlled trials (RCTs) involving 290 gastric cancer and 8 observational studies, totaling 7,321 gastric cancers indicated a reduced risk of gastric cancer with statin use (45). In addition, a meta-analysis of published studies showed a modest reduction in colorectal cancer risk among statin users (46).

A review of 723 patients diagnosed with primary inflammatory breast cancer in 1995-2011 showed that hydrophilic statins were associated with significantly improved progression-free survival (PFS) rates (47). However, long-term use of statins was associated with increased risk of invasive ductal carcinoma (IDC; $\mathrm{n}=916$ ) and invasive lobular carcinoma (ILC; $\mathrm{n}=1,068$ ) in a contemporary population-based case-control study conducted in the Seattle-Puget Sound region. It was also reported that women diagnosed with hypercholesterolemia currently using statins for $\geq 10$ years had more than double the risk of IDC (OR, 2.04, 95\% CI, 1.17-3.57) and ILC (OR, 2.43, 95\% CI, 1.40-4.21) compared with never users (48).

In the meta-analysis of all the observational studies published up to January 2012, statin use and long-term statin use did not significantly affect breast cancer risk. However, the cumulative meta-analysis showed a change in trend of reporting risk of breast cancer from positive to negative in statin users between 1993 and 2011. These findingd do not support the hypothesis that statins exert a protective effect against breast cancer (49).

The Cancer in The Ovary and Uterus Study (CITOUS; case-control study) assessed the use of statins prior to and following diagnosis in a subset of 424 cases of ovarian and endometrial cancers and 341 controls using pharmacy records. Use of statins $>1$ year prior to diagnosis was associated with risk reduction, whereas survival improvement was observed among the two malignancies when statins were ingested only after diagnosis (50).

The Nurses' Health and Health Professionals Follow-Up Study investigated the association between statin use and renal cell carcinoma (RCC) risk. The reported results were similar between ever vs. never users of statins. The subgroup analyses of that study reported that statin use may be associated with a lower risk of RCC among women with no history of hypertension (51). 
Statin use is associated with a reduced risk of hepatocellular cancer, most strongly in Asian, but also in Western populations (52). Similarly, another meta-analysis suggested a favorable effect of statins on hepatocellular carcinoma in the absence of a duration-risk relationship (53).

A meta-analysis of all the published articles up to December 2007 showed no association between statin use on pancreatic cancer risk among patients using statins daily for managing hypercholesterolemia (54). These findings were consistent with those from another meta-analysis, which reported no association between statin use and pancreatic cancer risk among patients using statins daily for preventing cardiovascular event (55).

A meta-analysis of observational trials and RCTs did not support a protective effect of statins on overall lung cancer risk, and the lung cancer risk among elderly people (56). Nineteen studies (5 RCTs and 14 observational studies) involving 38,013 lung cancer cases suggested no association between statin use and risk of lung cancer (57). Similarly, a meta-analysis of published literature did not support the role of statins in prevention of skin cancer (58).

A retrospective evaluation of 1,502 patients with urothelial carcinoma of the bladder treated with radical cystectomy and pelvic lymphadenectomy without neoadjuvant therapy showed statin users were at a higher risk for disease recurrence and cancer-specific mortality in a univariate, but not a multivariate analysis. However, the present study also reported that statin users were older $(\mathrm{P}=0.003)$, had higher body mass index (median $32 \mathrm{vs} .28 \mathrm{~kg} / \mathrm{m}^{2}, \mathrm{P}<0.001$ ), and were more likely to have positive soft tissue surgical margins (9 vs. 4\%, $\mathrm{P}<0.001$ ) (59). Another meta-analysis with limited RCTs suggested no association between statin use and risk of bladder cancer (60).

Numerous population-based case-control studies conducted in Taiwan did not provide evidence to support an association between statin use and risk of breast cancer ( $n=565$; control, $\mathrm{n}=2,260)(61)$, esophageal cancer $(\mathrm{n}=197$; controls, $\mathrm{n}=788)(62)$, bladder cancer $(n=325$; controls, $n=1,300)$ (63), kidney cancer $(n=177$; controls, $n=708)(64)$, and female lung cancer $(n=297$; controls, $n=1,188)(65)$.

Another retrospective evaluation of the entire Danish population diagnosed with cancer between 1995 and 2007 was performed on 18,721 patients using statins regularly before the cancer diagnosis vs. 277,204 patients who had never used statins. The present study concluded that statin use in cancer patients was associated with reduced cancer-associated mortality as compared to that in non-users (HR, 0.85, 95\% CI, 0.82-0.87) for each of the 13 types of cancer (66). In another meta-analysis (27 randomized trials), a median of 5 years of statin therapy was reported to have no effect on the incidence of, or mortality from, any type of cancer, or the aggregate of all cancers (67). The effect of statins on the incidence of different types of cancer reported in various observational and retrospective studies is presented in Table II.

\section{Antitumor effect of statins in experimental studies}

Lovastatin. In a phase I-II trial of lovastatin in anaplastic astrocytoma and glioblastoma multiforme, 18 patients received lovastatin between 20 and $30 \mathrm{mg} / \mathrm{kg} /$ day for 7 days followed by a 3 -week rest. Lovastatin was considered well tolerated, as no patient reported myalgia and only 2 patients reported mild joint pain. Nine of 18 patients received concurrent radiation with no neurological toxicity, indicating that the combination was potentially safe. Of those who received concurrent radiation, 2 minor and 2 partial responses (duration range, 160-236 days) were observed. One patient each on lovastatin monotherapy showed partial and minor response, and stable disease. Notably, the patient who had partial response accomplished a response duration of $>405$ days, at which time lovastatin was discontinued due to cost-related issues (68).

Similarly, another phase I study evaluated the safety and tolerability of lovastatin using escalating doses in 88 cancer patients with advanced solid tumors. A majority of patients had prostate cancer or central nervous system tumors. Myopathy was found to be a dose-limiting toxicity and ubiquinone administration was associated with reversal of lovastatininduced myopathy. Myopathy was prevented by its prophylactic administration in a 56-patient cohort. In the absence of supplementation, lovastatin was well tolerated up to $25 \mathrm{mg} / \mathrm{kg} / \mathrm{day}$ for 7 days followed by a 3 -week rest. One anaplastic astrocytoma patient treated with lovastatin at 30 and $35 \mathrm{mg} / \mathrm{kg} /$ day who progressed after surgical resection of the tumor, irradiation and 2 cycles of carmustine had a minor response (45\% tumor size reduction) maintained for 8 months (69).

Prolongation of overall survival and PFS was documented in MM patients with lovastatin plus thalidomide and dexamethasone (TDL) vs. thalidomide and dexamethasone alone. The TDL regimen was safe and well tolerated (70).

Simvastatin. Simvastatin in combination with conventional FOLFIRI [irinotecan, 5-fluorouracil (5-FU), and leucovorin] in metastatic colorectal cancer patients showed promising antitumor activities (71). An exploratory subgroup analysis in non-small cell lung carcinoma patients with wild-type epidermal growth factor receptor (EGFR) non-adenocarcinomas showed higher RR, 40 vs. $0 \%, \mathrm{P}=0.043$ ) and longer PFS (3.6 vs. 1.7 months, $\mathrm{P}=0.027$ ) with simvastatin plus gefitinib vs. gefitinib alone (72). Moreover, low-dose simvastatin to gemcitabine in advanced pancreatic cancer does not provide clinical benefit or results in increased toxicity (73).

Atorvastatin. The 6-month interventions with atorvastatin did not provide convincing evidence of colorectal cancer risk reduction in a multicenter phase II trial, although the relatively small sample size limited statistical power (74).

Fluvastatin. In patients with RCC and metastasis, zoledronate with fluvastatin or atorvastatin as bone-targeting therapy affected certain bone biomarkers and provided bone response in several patients. However, no statistically significant improvement in time to skeletal events was observed (75). The survival of pediatric brain stem tumor patients was significantly increased with metronomic treatment with carboplatin and vincristine associated with fluvastatin and thalidomide (76).

Pravastatin. In patients with acute myeloid leukemia (AML), pravastatin with idarubicin plus high-dose cytarabine (Ida-HDAC) decreased the total and low-density lipoprotein (LDL) cholesterol in almost all patients. The encouraging response rates suggest further trials evaluating the effect of cholesterol modulation on response in AML should be conducted (77). Chemoembolization and pravastatin combination significantly improved $(\mathrm{P}=0.003)$ survival of patients with advanced hepatocellular carcinoma vs. those receiving chemoembolization alone (78). 


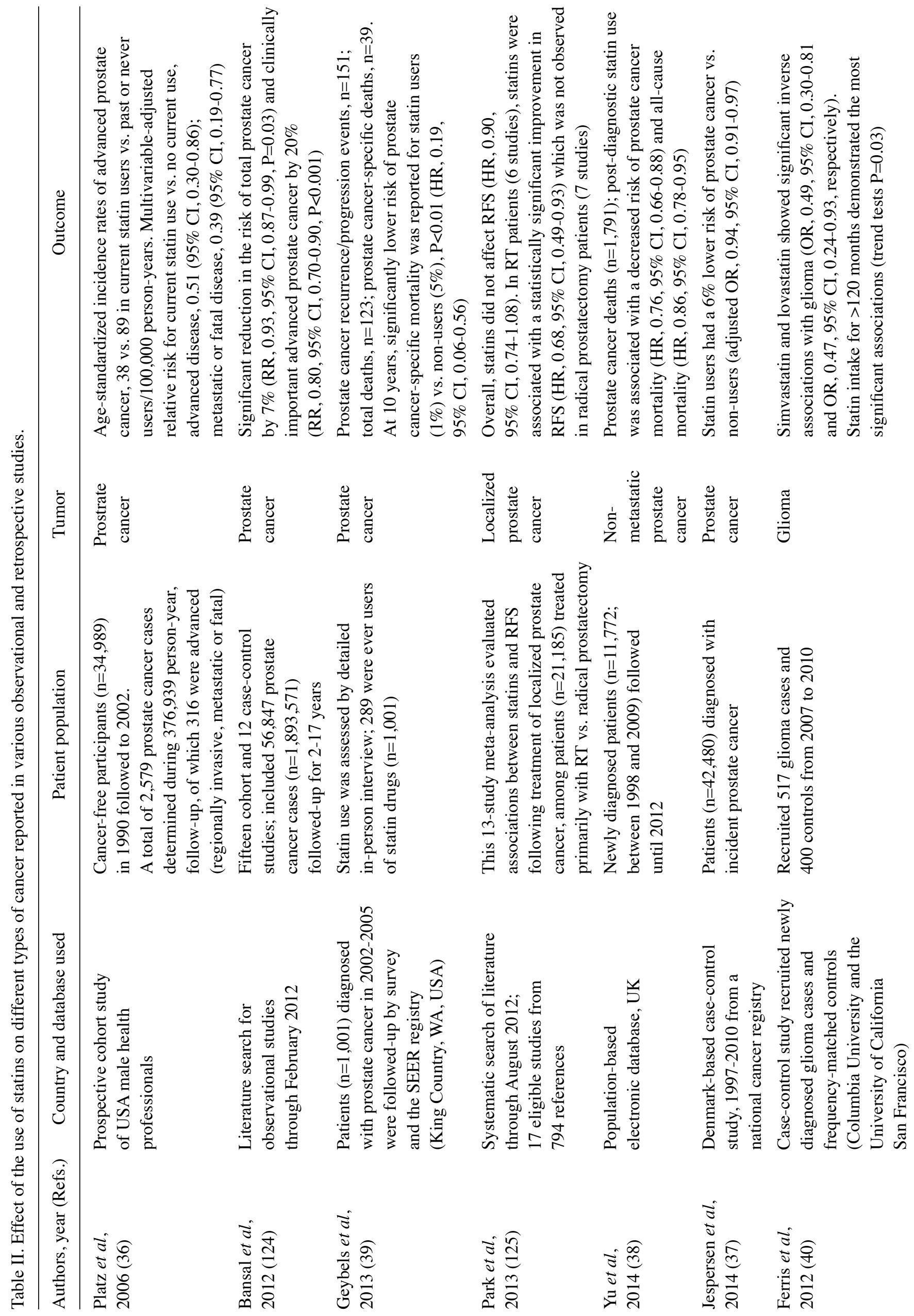




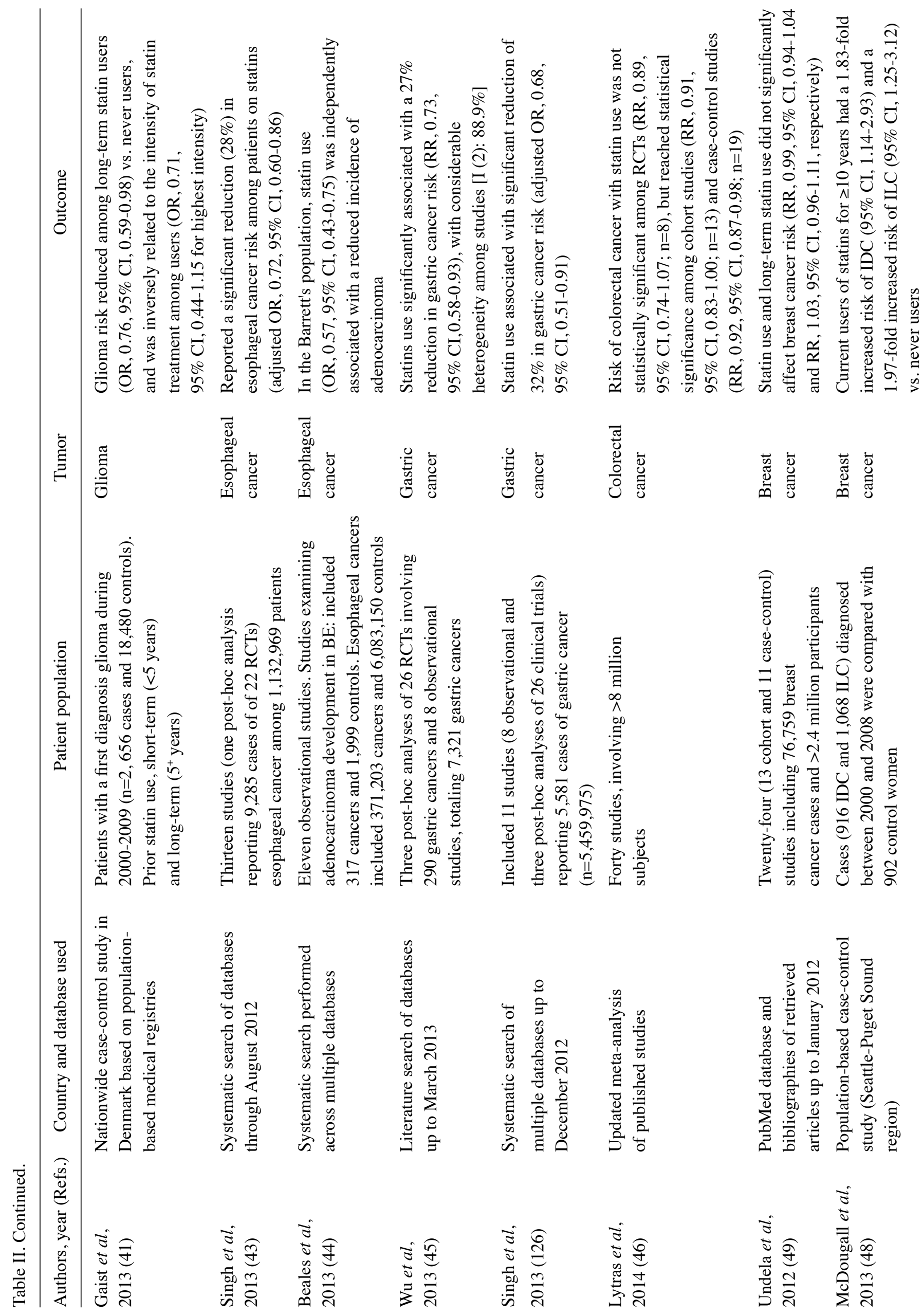




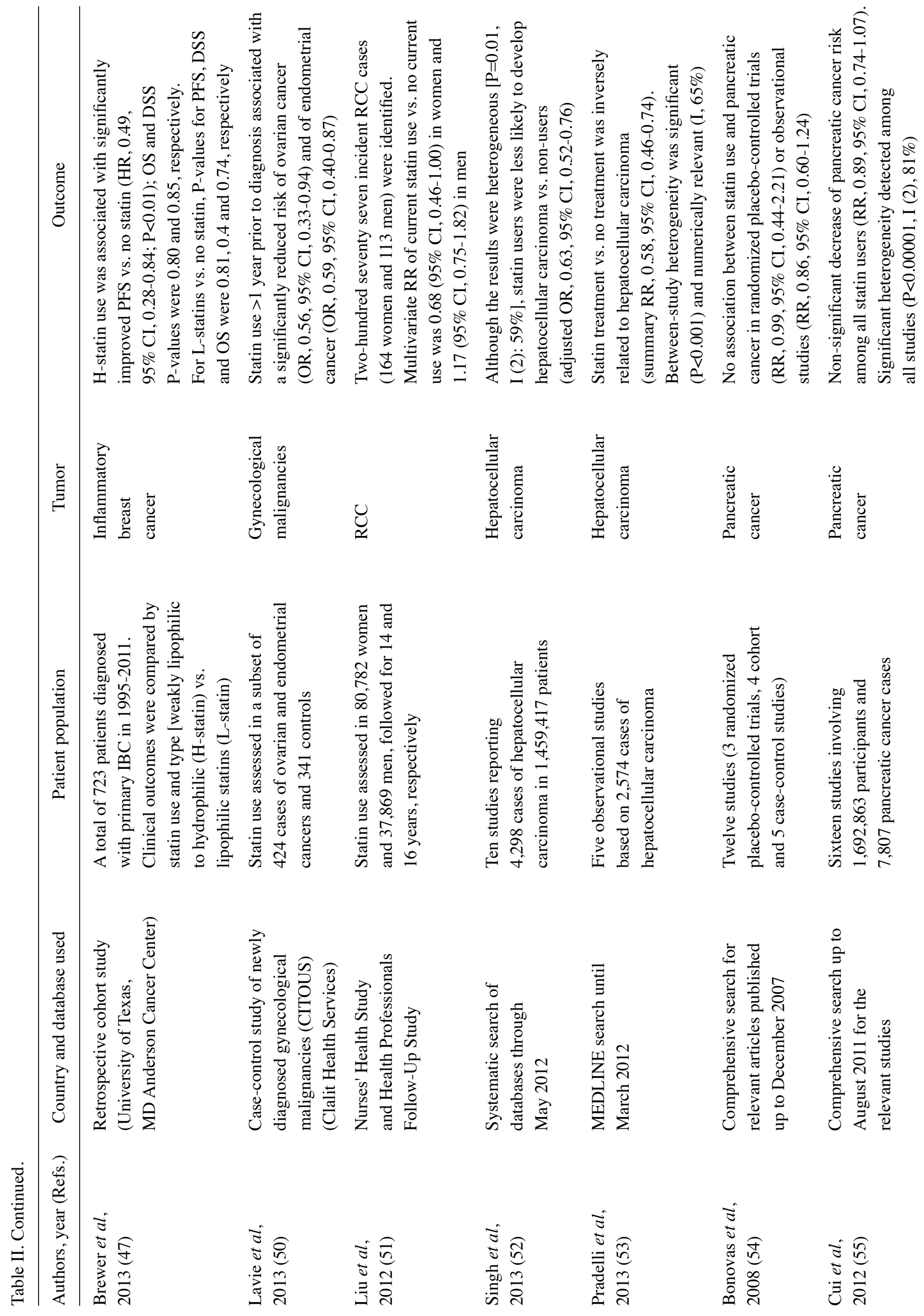




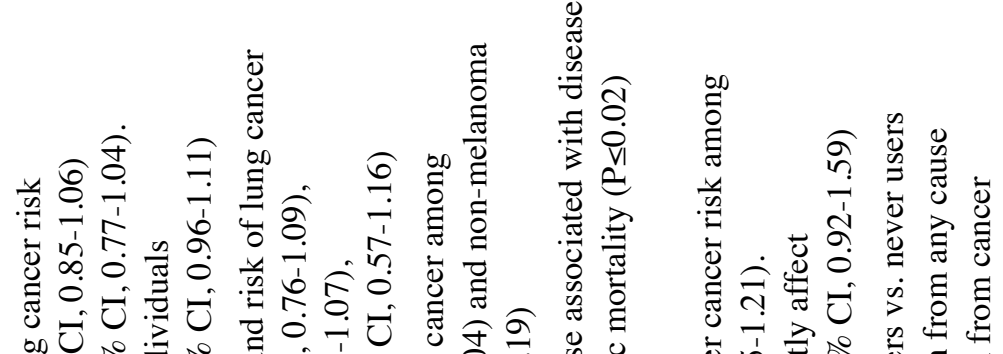
on 当

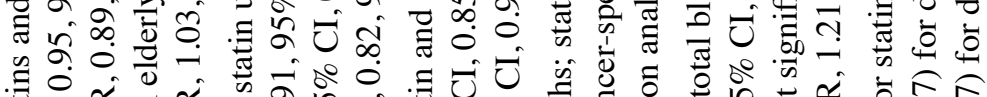

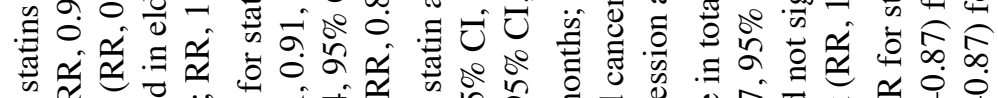

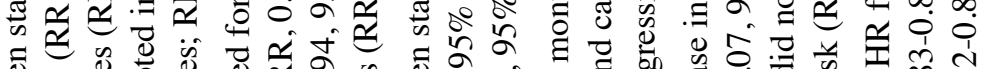
बै.

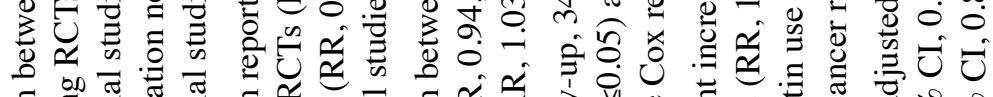

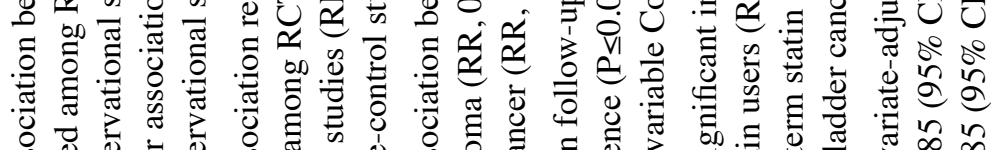

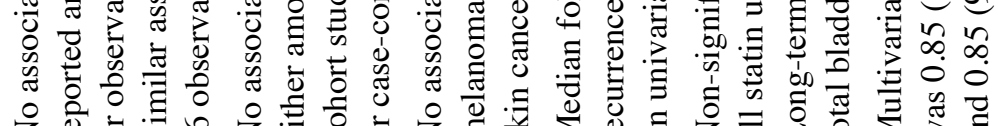

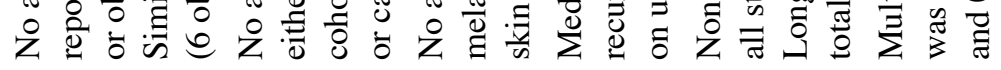

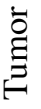
ט $\stackrel{\infty}{\Xi} \underset{\Xi}{\Xi}$ 卷

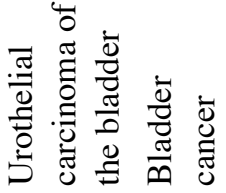

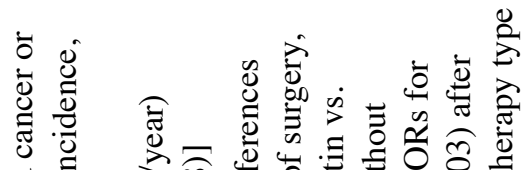
ग.

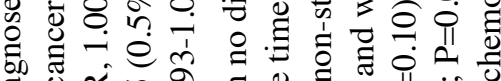

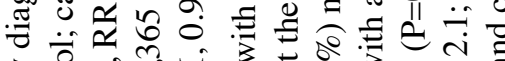
入

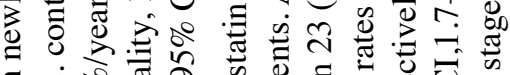

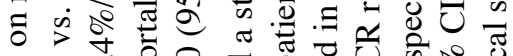

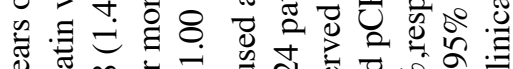
入 ? 递它 .

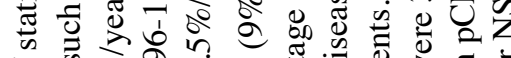

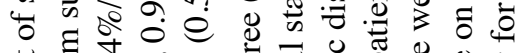

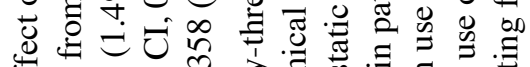

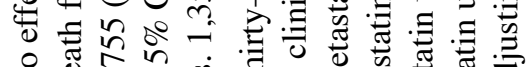

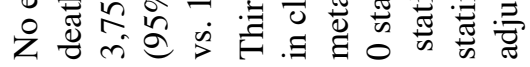

: 2

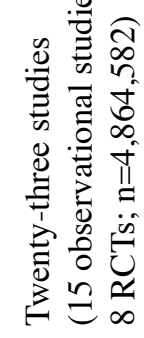

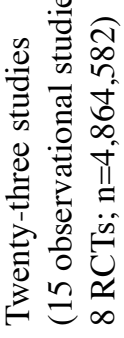

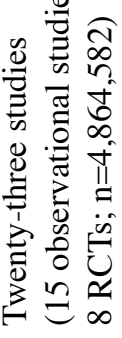

$\stackrel{0}{*}$
를 ્ֻల 0 䒕 पे

을

ป

言

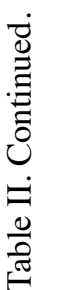

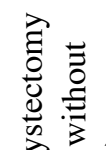

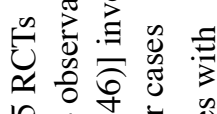

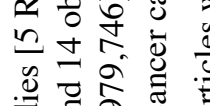

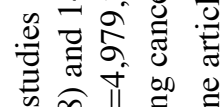

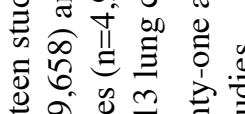

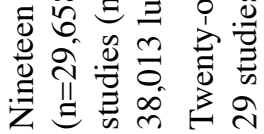

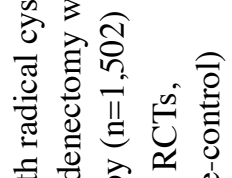

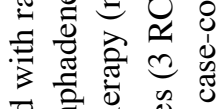

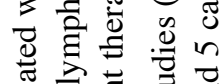

冚总芯 总

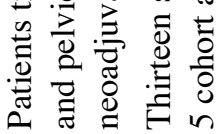

ठ্ঠ

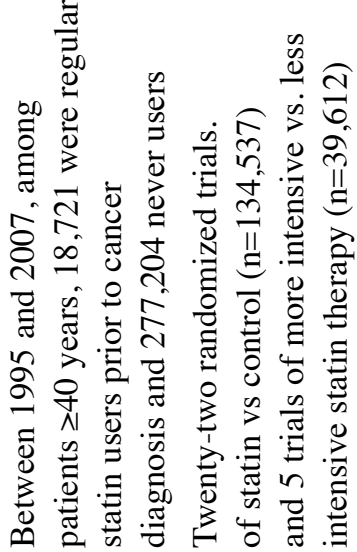

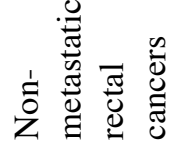

흘

$$
\text { 然 }
$$<smiles>C1CC[Si]C1</smiles>

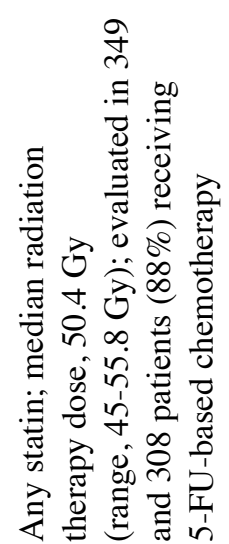


Pravastatin in combination with epirubicin, cisplatin, and capecitabine did not improve outcome in advanced gastric cancer patients in a randomized phase II trial (79). Summary of clinical trials that used statins as monotherapy or as a combination in patients with different cancer types are presented in Table III.

\section{Synergism of statins with radiotherapy and chemotherapy}

Statins act by arresting cells in the late G1 phase of the cell cycle and can affect cell synchronization in the radiosensitive phase (5). The late G1 and G2-M phases are most sensitive to radiation therapy; therefore, statins potentially sensitized cells to radiation in the late $\mathrm{G} 1$ phase $(80,81)$. The antitumor effect of lovastatin as a radiosensitizer on B-cell rat lymphoma (L-TACB) was higher than that of individual therapy (82). The underlying molecular mechanism involved Ras, which confers intrinsic resistance to radiation since in vitro studies using osteosarcoma cells demonstrated that lovastatin decreases this radiation resistance $(80,81)$. Furthermore, HMGCR may serve as a predictive marker of response to postoperative radiotherapy in ductal carcinoma in situ (DCIS) (83). A retrospective cohort study suggested an association between statin therapy and improvement in response of rectal cancer to neoadjuvant chemoradiation (84).

Statins have shown anticancer potential with numerous chemotherapeutic agents. Simvastatin showed additive activity and mutual sensitization with doxorubicin by triggering caspase activation in human rhabdomyosarcoma cells (85). When combined with 5-FU or cisplatin as chemotherapy, lovastatin acts by inhibiting geranylgeranylation but not farnesylation of target protein(s) in colon cancer cells (10). Lovastatin or simvastatin with cytosine arabinoside significantly enhances the antiproliferative effect of each drug in leukemia cell lines and this may be beneficial in the leukemia treatment $(86,87)$. A similar synergy of simvastatin with $N, N^{\prime}$-bis(2-chloroethyl)$N$-nitrosourea or $\beta$-interferon produces antiproliferative activity in human glioma cells (88). Cerivastatin also increases the cytotoxicity of 5-FU in chemoresistant colorectal cancer cell lines by inhibiting nuclear factor- $\mathrm{\kappa B}$ DNA-binding activity (89).

A phase I study in AML patients showed synergistic effects of the addition of pravastatin to a conventional chemotherapy regimen (idarubicin and high-dose cytarabine) (77). Statin use in combination with concurrent chemoradiotherapy in preoperative rectal carcinoma patients was associated with improved pathologic complete response at the time of surgery (90). HMGCR expression was reported as an independent predictor of prolonged recurrence-free survival in primary ovarian cancer. Future studies are required to evaluate HMGCR expression as a surrogate marker of response to statin treatment, particularly in conjunction with current chemotherapeutic regimens (91). Synergistic effects are observed in patients with relapsed or refractory myeloma by the addition of lovastatin to thalidomide and dexamethasone (70).

\section{Conclusion}

Preclinical data based on cancer cell lines and animal models demonstrate encouraging anticancer activity of statins. 


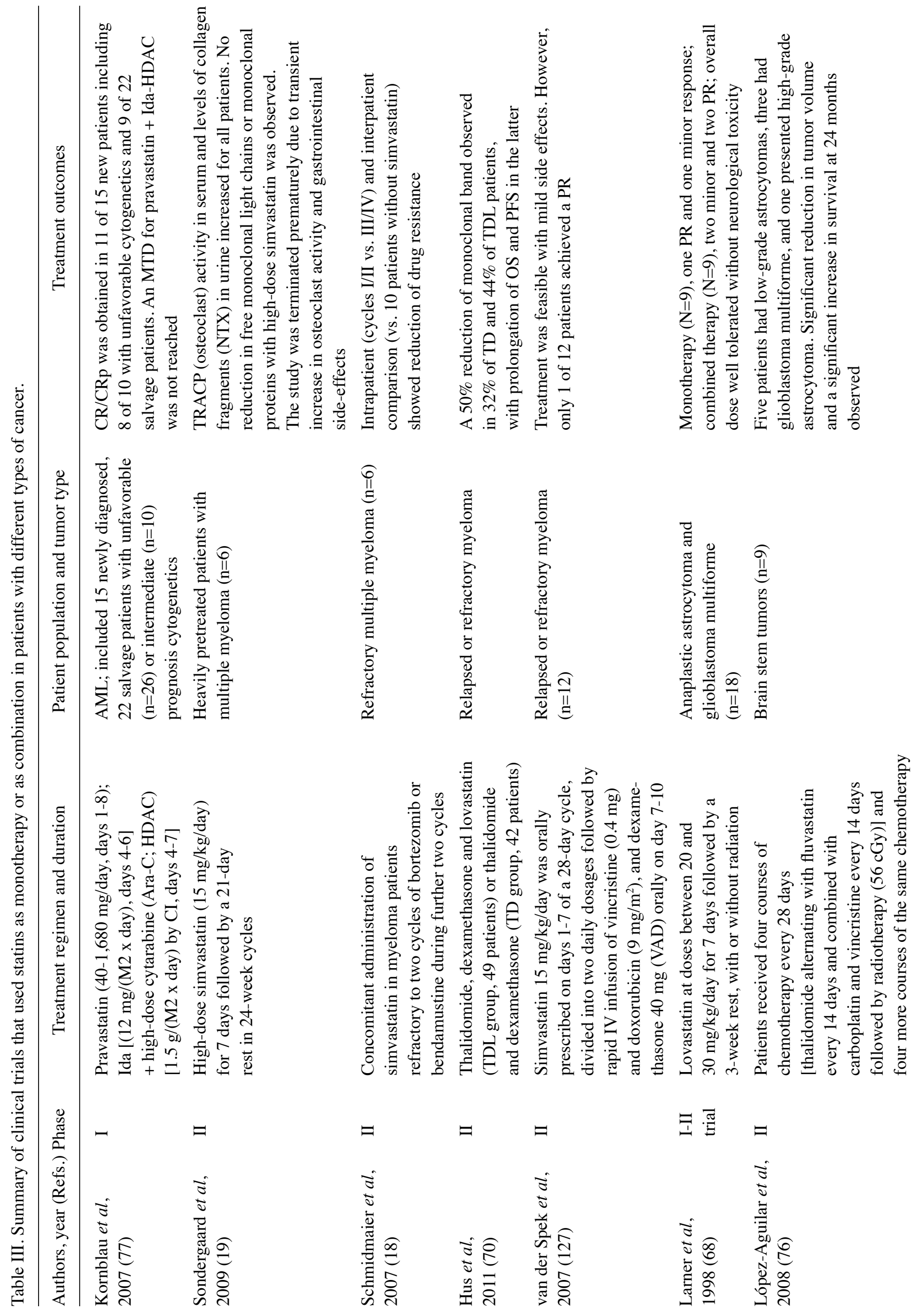




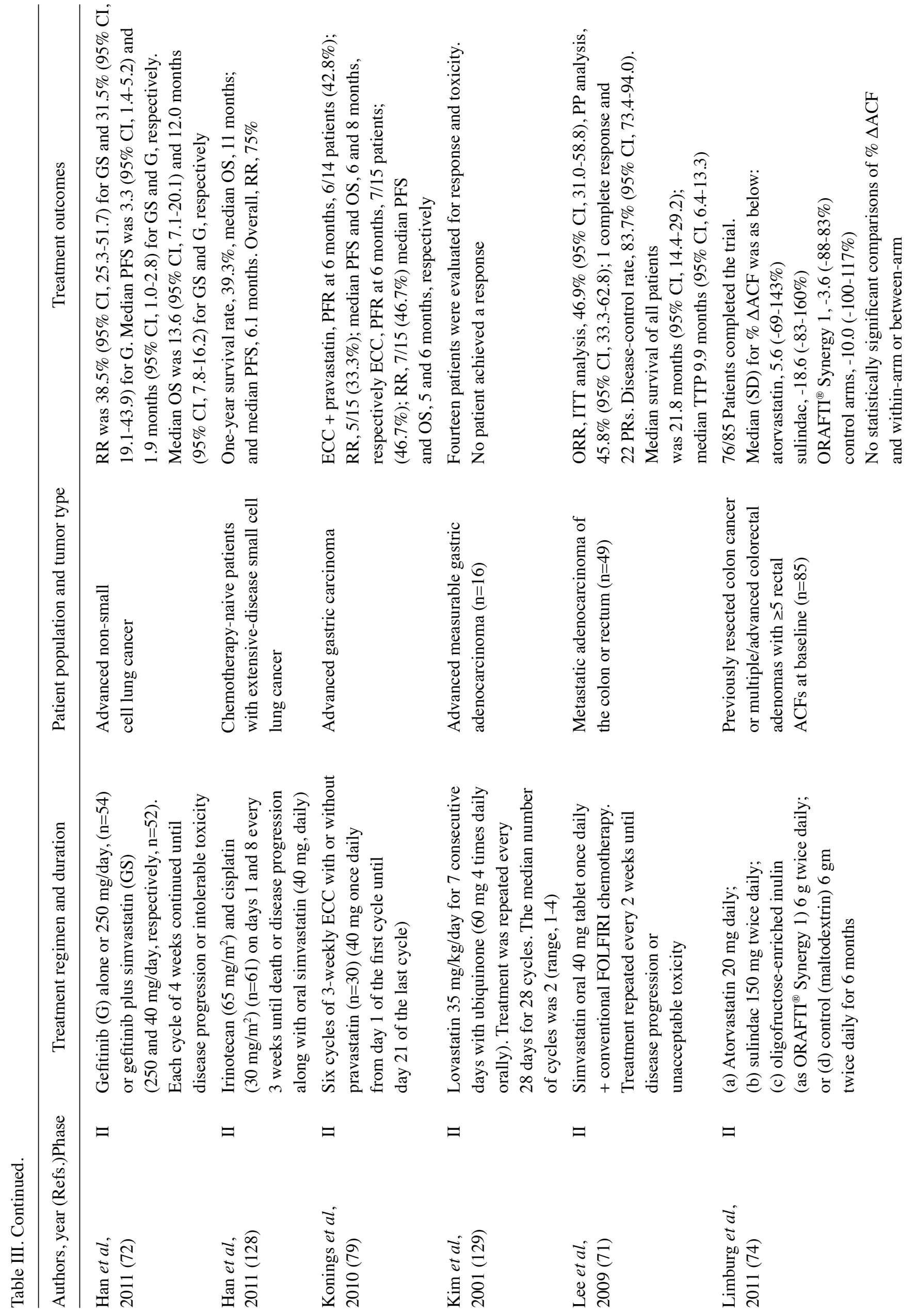




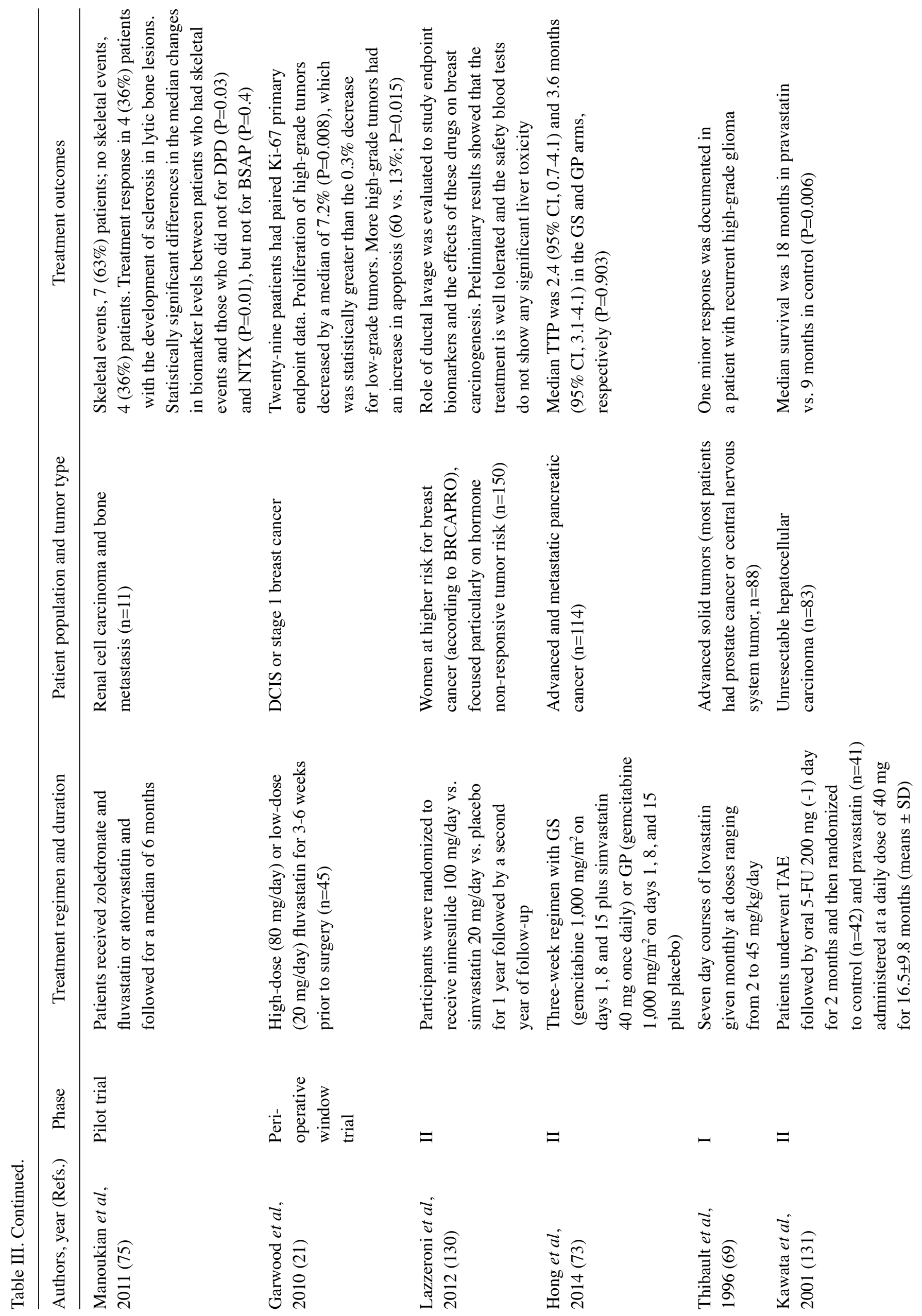


Similarly, several population-based and retrospective studies demonstrate chemopreventive and survival benefit of statins in various types of cancer. However, this benefit has not been confirmed/proven or validated in clinical trials, and is attributed to the absence of well-conducted large-scale phase III RCTs that have addressed the antitumor effects of statins in cancer. In fact, a majority of the trials thus far are phase I and/or small or poorly conducted phase II clinical trials with a small sample size and inadequate power. Moreover, genetic and non-genetic factors also may contribute to the inter-individual variation in statin response. In ovarian cancer, HMGCR expression was reported as an independent predictor of prolonged recurrence-free survival (91). Lipkin et al, identified a single-nucleotide polymorphism in the $H M G C R$ gene that significantly modified the chemopreventive activity of statins for colorectal cancer risk (92). Heterogeneous nuclear ribonucleoprotein A1 (HNRNPA1) overexpression was recently reported to reduce HMGCR enzyme activity, enhance LDL-C uptake, and increase cellular apolipoprotein B (93). This may explain the inter-individual variation of drug response to statins. Advances in molecular biology may be useful to identify markers responsive to statin treatment and tailor base statin treatment based on genotypic profile, in the direction of personalized medicine.

Studies suggest statins can modulate the outcome of various cancer types and notably can target cancer vs. normal cells. The microenvironments seem to regulate the statin effect in different types of cancer. The side-effects appear to be limited, manageable and may be associated with genetic and non-genetic factors. Future studies should concentrate on evaluating statins in large-scale phase III RCTs in cancer patients to establish the precise effect of stains in cancer prevention and treatment.

\section{Acknowledgements}

This study was supported in part by King Fahad Medical City, Riyadh, Saudi Arabia.

\section{References}

1. Ferlay J, Soerjomataram I, Ervik M, et al: GLOBOCAN 2012 v1.0, Cancer Incidence and Mortality Worldwide: IARC CancerBase No. 11 (Internet). Lyon, France: International Agency for Research on Cancer. 2013. Available from: http:// globocan.iarc.fr. Accessed.

2. Kanu OO, Mehta A, Di C, Lin N, et al: Glioblastoma multiforme: a review of therapeutic targets. Expert Opin Ther Targets 13: 701-718, 2009.

3. Goldstein JL and Brown MS: Regulation of the mevalonate pathway. Nature 343: 425-430, 1990.

4. Gazzerro P, Proto MC, Gangemi G, et al: Pharmacological actions of statins: a critical appraisal in the management of cancer. Pharmacol Rev 64: 102-146, 2012.

5. Chan KK, Oza AM and Siu LL: The statins as anticancer agents. Clin Cancer Res 9: 10-19, 2003.

6. Baserga R: Molecular biology of the cell cycle. Int J Radiat Biol Relat Stud Phys Chem Med 49: 219-226, 1986.

7. Tapia-Pérez JH, Kirches E, Mawrin C, Firsching R and Schneider T: Cytotoxic effect of different statins and thiazolidinediones on malignant glioma cells. Cancer Chemother Pharmacol 67: 1193-1201, 2011.

8. Rao S, Lowe M, Herliczek TW and Keyomarsi K: Lovastatin mediated G1 arrest in normal and tumor breast cells is through inhibition of CDK2 activity and redistribution of p21 and p27, independent of p53. Oncogene 17: 2393-2402, 1998. 
9. Collisson EA, Kleer C, Wu M, et al: Atorvastatin prevents RhoC isoprenylation, invasion, and metastasis in human melanoma cells. Mol Cancer Ther 2: 941-948, 2003.

10. Agarwal B, Bhendwal S, Halmos B, Moss SF, Ramey WG and Holt PR: Lovastatin augments apoptosis induced by chemotherapeutic agents in colon cancer cells. Clin Cancer Res 5: 2223-2229, 1999.

11. Marcelli M, Cunningham GR, Haidacher SJ, et al: Caspase-7 is activated during lovastatin-induced apoptosis of the prostate cancer cell line LNCaP. Cancer Res 58: 76-83, 1998.

12. Koyuturk M, Ersoz M and Altiok N: Simvastatin induces apoptosis in human breast cancer cells: $\mathrm{p} 53$ and estrogen receptor independent pathway requiring signalling through JNK. Cancer Lett 250: 220-228, 2007.

13. Baetta R, Donetti E, Comparato C, et al: Pro-apoptotic effect of atorvastatin on stimulated rabbit smooth muscle cells. Pharmacol Res 36: 115-121, 1997.

14. Wang IK, Lin-Shiau SY and Lin JK: Induction of apoptosis by lovastatin through activation of caspase-3 and DNase II in leukaemia HL-60 cells. Pharmacol Toxicol 86: 83-91, 2000.

15. He Z, Mangala LS, Theriot CA, Rohde LH, Wu H and Zhang Y: Cell killing and radiosensitizing effects of atorvastatin in PC3 prostate cancer cells. J Radiat Res 53: 225-233, 2012.

16. Denoyelle C, Vasse M, Körner M, et al: Cerivastatin, an inhibitor of HMG-CoA reductase, inhibits the signaling pathways involved in the invasiveness and metastatic properties of highly invasive breast cancer cell lines: an in vitro study. Carcinogenesis 22 $1139-1148,2001$.

17. Bouterfa HL, Sattelmeyer V, Czub S, Vordermark D, Roosen K and Tonn JC: Inhibition of Ras farnesylation by lovastatin leads to downregulation of proliferation and migration in primary cultured human glioblastoma cells. Anticancer Res 20: 2761-2771, 2000.

18. Schmidmaier R, Baumann P, Bumeder I, Meinhardt G, Straka C and Emmerich B: First clinical experience with simvastatin to overcome drug resistance in refractory multiple myeloma. Eur J Haematol 79: 240-243, 2007.

19. Sondergaard TE, Pedersen PT, Andersen TL, et al: A phase II clinical trial does not show that high dose simvastatin has beneficial effect on markers of bone turnover in multiple myeloma. Hematol Oncol 27: 17-22, 2009.

20. Bjarnadottir O, Romero Q, Bendahl PO, et al: Targeting HMG-CoA reductase with statins in a window-of-opportunity breast cancer trial. Breast Cancer Res Treat 138: 499-508, 2013.

21. Garwood ER, Kumar AS, Baehner FL, et al: Fluvastatin reduces proliferation and increases apoptosis in women with high grade breast cancer. Breast Cancer Res Treat 119: 137-144, 2010.

22. Inano H, Suzuki K, Onoda M and Wakabayashi K: Anticarcinogenic activity of simvastatin during the promotion phase of radiation-induced mammary tumorigenesis of rats. Carcinogenesis 18: 1723-1727, 1997.

23. Narisawa T, Fukaura Y, Tanida N, Hasebe M, Ito M and Aizawa R: Chemopreventive efficacy of low dose of pravastatin, an HMG-CoA reductase inhibitor, on 1,2-dimethylhydrazineinduced colon carcinogenesis in ICR mice. Tohoku J Exp Med 180: 131-138, 1996

24. Narisawa T, Morotomi M, Fukaura Y, Hasebe M, Ito M and Aizawa R: Chemoprevention by pravastatin, a 3-hydroxy3-methylglutaryl-coenzyme A reductase inhibitor, of $\mathrm{N}$-methyl-N-nitrosourea-induced colon carcinogenesis in F344 rats. Jpn J Cancer Res 87: 798-804, 1996.

25. Clutterbuck RD, Millar BC, Powles RL, et al: Inhibitory effect of simvastatin on the proliferation of human myeloid leukaemia cells in severe combined immunodeficient (SCID) mice. Br J Haematol 102: 522-527, 1998.

26. Kikuchi T, Nagata $\mathrm{Y}$ and Abe T: In vitro and in vivo antiproliferative effects of simvastatin, an HMG-CoA reductase inhibitor on human glioma cells. J Neurooncol 34: 233-239, 1997.

27. Hawk MA, Cesen KT, Siglin JC, Stoner GD and Ruch RJ: Inhibition of lung tumor cell growth in vitro and mouse lung tumor formation by lovastatin. Cancer Lett 109: 217-222, 1996.

28. Matar P, Rozados VR, Binda MM, Roggero EA, Bonfil RD and Scharovsky OG: Inhibitory effect of lovastatin on spontaneous metastases derived from a rat lymphoma. Clin Exp Metastasis 17: $19-25,1999$.

29. Matar P, Rozados VR, Roggero EA and Scharovsky OG: Lovastatin inhibits tumor growth and metastasis development of a rat fibrosarcoma. Cancer Biother Radiopharm 13: 387-393, 1998.
30. Alonso DF, Farina HG, Skilton G, Gabri MR, De Lorenzo MS and Gomez DE: Reduction of mouse mammary tumor formation and metastasis by lovastatin, an inhibitor of the mevalonate pathway of cholesterol synthesis. Breast Cancer Res Treat 50: 83-93, 1998.

31. Broitman SA, Wilkinson JT IV, Cerda S and Branch SK: Effects of monoterpenes and mevinolin on murine colon tumor CT-26 in vitro and its hepatic 'metastases' in vivo. Adv Exp Med Biol 401: 111-130, 1996

32. Jani JP, Specht S, Stemmler N, et al: Metastasis of B16F10 mouse melanoma inhibited by lovastatin, an inhibitor of cholesterol biosynthesis. Invasion Metastasis 13: 314-324, 1993.

33. Feleszko W, Mlynarczuk I, Balkowiec-Iskra EZ, et al: Lovastatin potentiates antitumor activity and attenuates cardiotoxicity of doxorubicin in three tumor models in mice. Clin Cancer Res 6: 2044-2052, 2000.

34. Feleszko W, Bałkowiec EZ, Sieberth E, et al: Lovastatin and tumor necrosis factor- $\alpha$ exhibit potentiated antitumor effects against Ha-ras-transformed murine tumor via inhibition of tumor-induced angiogenesis. Int J Cancer 81: 560-567, 1999.

35. Mucci LA and Stampfer MJ: Mounting evidence for prediagnostic use of statins in reducing risk of lethal prostate cancer. J Clin Oncol 32: 1-2, 2014

36. Platz EA, Leitzmann MF, Visvanathan K, et al: Statin drugs and risk of advanced prostate cancer. J Natl Cancer Inst 98: $1819-1825,2006$.

37. Jespersen CG, Norgaard M, Friis S, Skriver C and Borre M: Statin use and risk of prostate cancer: a Danish population-based case-control study, 1997-2010. Cancer Epidemiol 38: 42-47, 2014.

38. Yu O, Eberg M, Benayoun S, et al: Use of statins and the risk of death in patients with prostate cancer. J Clin Oncol 32: 5-11, 2014.

39. Geybels MS, Wright JL, Holt SK, Kolb S, Feng Z and Stanford JL: Statin use in relation to prostate cancer outcomes in a populationbased patient cohort study. Prostate 73: 1214-1222, 2013.

40. Ferris JS, McCoy L, Neugut AI, Wrensch M and Lai R: HMG CoA reductase inhibitors, NSAIDs and risk of glioma. Int $\mathrm{J}$ Cancer 131: E1031-E1037, 2012.

41. Gaist D, Andersen L, Hallas J, Sørensen HT, Schroder HD and Friis S: Use of statins and risk of glioma: a nationwide casecontrol study in Denmark. Br J Cancer 108: 715-720, 2013.

42. Tsibouris P, Vlachou E and Isaacs PE: Role of chemoprophylaxis with either NSAIDs or statins in patients with Barrett's esophagus. World J Gastrointest Pharmacol Ther 5: 27-39, 2014.

43. Singh S, Singh AG, Singh PP, Murad MH and Iyer PG: Statins are associated with reduced risk of esophageal cancer, particularly in patients with Barrett's esophagus: a systematic review and meta-analysis. Clin Gastroenterol Hepatol 11: 620-629, 2013.

44. Beales IL, Hensley A and Loke Y: Reduced esophageal cancer incidence in statin users, particularly with cyclo-oxygenase inhibition. World J Gastrointest Pharmacol Ther 4: 69-79, 2013.

45. Wu XD, Zeng K, Xue FQ, Chen JH and Chen YQ: Statins are associated with reduced risk of gastric cancer: a meta-analysis. Eur J Clin Pharmacol 69: 1855-1860, 2013.

46. Lytras T, Nikolopoulos G and Bonovas S: Statins and the risk of colorectal cancer: an updated systematic review and metaanalysis of 40 studies. World J Gastroenterol 20: 1858-1870, 2014.

47. Brewer TM, Masuda H, Liu DD, et al: Statin use in primary inflammatory breast cancer: a cohort study. Br J Cancer 109: 318-324, 2013.

48. McDougall JA, Malone KE, Daling JR, Cushing-Haugen KL, Porter PL and Li CI: Long-term statin use and risk of ductal and lobular breast cancer among women 55 to 74 years of age. Cancer Epidemiol Biomarkers Prev 22: 1529-1537, 2013.

49. Undela K, Srikanth V and Bansal D: Statin use and risk of breast cancer: a meta-analysis of observational studies. Breast Cancer Res Treat 135: 261-269, 2012

50. Lavie O, Pinchev M, Rennert HS, Segev Y and Rennert G: The effect of statins on risk and survival of gynecological malignancies. Gynecol Oncol 130: 615-619, 2013.

51. Liu W, Choueiri TK and Cho E: Statin use and the risk of renal cell carcinoma in 2 prospective US cohorts. Cancer 118: 797-803, 2012.

52. Singh S, Singh PP, Singh AG, Murad MH and Sanchez W: Statins are associated with a reduced risk of hepatocellular cancer: a systematic review and meta-analysis. Gastroenterology 144: 323-332, 2013. 
53. Pradelli D, Soranna D, Scotti L, et al: Statins and primary liver cancer: a meta-analysis of observational studies. Eur J Cancer Prev 22: 229-234, 2013.

54. Bonovas S, Filioussi K and Sitaras NM: Statins are not associated with a reduced risk of pancreatic cancer at the population level, when taken at low doses for managing hypercholesterolemia: evidence from a meta-analysis of 12 studies Am J Gastroenterol 103: 2646-2651, 2008.

55. Cui X, Xie Y, Chen M, et al: Statin use and risk of pancreatic cancer: a meta-analysis. Cancer Causes Control 23: 1099-1111, 2012.

56. Deng Z, Zhang S, Yi L and Chen S: Can statins reduce risk of lung cancer, especially among elderly people? A meta-analysis. Chin J Cancer Res 25: 679-688, 2013.

57. Tan M, Song X, Zhang G, et al: Statins and the risk of lung cancer: a meta-analysis. PLoS One 8: e57349, 2013.

58. $\mathrm{Li} \mathrm{X}, \mathrm{Wu} \mathrm{XB}$ and Chen Q: Statin use is not associated with reduced risk of skin cancer: a meta-analysis. Br J Cancer 110: 802-807, 2014

59. da Silva RD, Xylinas E, Kluth L, et al: Impact of statin use on oncologic outcomes in patients with urothelial carcinoma of the bladder treated with radical cystectomy. J Urol 190: 487-492, 2013.

60. Zhang XL, Geng J, Zhang XP, et al: Statin use and risk of bladder cancer: a meta-analysis. Cancer Causes Control 24: 769-776, 2013.

61. Chan TF, Wu CH, Lin CL and Yang CY: Statin use and the risk of breast cancer: a population-based case-control study. Expert Opin Drug Saf 13: 287-293, 2014.

62. Chan TF, Chiu HF, Wu CH, Lin CL and Yang CY: Statin use and the risk of esophageal cancer: a population-based case-control study. Expert Opin Drug Saf 12: 293-298, 2013.

63. Kuo CC, Chiu HF, Lee IM, Kuo HW, Lee CT and Yang CY: Statin use and the risk of bladder cancer: a population-based case-control study. Expert Opin Drug Saf 11: 733-738, 2012.

64. Chiu HF, Kuo CC, Kuo HW, Lee IM, Lee CT and Yang CY: Statin use and the risk of kidney cancer: a population-based case-control study. Expert Opin Drug Saf 11: 543-549, 2012.

65. Cheng MH, Chiu HF, Ho SC and Yang CY: Statin use and the risk of female lung cancer: a population-based case-control study. Lung Cancer 75: 275-279, 2012.

66. Nielsen SF, Nordestgaard BG and Bojesen SE: Statin use and reduced cancer-related mortality. N Engl J Med 367: 1792-1802, 2012.

67. Cholesterol Treatment Trialists' (CTT) Collaboration; Emberson JR, Kearney PM, Blackwell L, et al: Lack of effect of lowering LDL cholesterol on cancer: meta-analysis of individual data from 175,000 people in 27 randomised trials of statin therapy. PLoS One 7: e29849, 2012.

68. Larner J, Jane J, Laws E, Packer R, Myers C and Shaffrey M: A phase I-II trial of lovastatin for anaplastic astrocytoma and glioblastoma multiforme. Am J Clin Oncol 21: 579-583, 1998.

69. Thibault A, Samid D, Tompkins AC, et al: Phase I study of lovastatin, an inhibitor of the mevalonate pathway, in patients with cancer. Clin Cancer Res 2: 483-491, 1996.

70. Hus M, Grzasko N, Szostek M, et al: Thalidomide, dexamethasone and lovastatin with autologous stem cell transplantation as a salvage immunomodulatory therapy in patients with relapsed and refractory multiple myeloma. Ann Hematol 90: 1161-1166, 2011.

71. Lee J, Jung KH, Park YS, et al: Simvastatin plus irinotecan, 5-fluorouracil, and leucovorin (FOLFIRI) as first-line chemotherapy in metastatic colorectal patients: a multicenter phase II study. Cancer Chemother Pharmacol 64: 657-663, 2009.

72. Han JY, Lee SH, Yoo NJ, et al: A randomized phase II study of gefitinib plus simvastatin versus gefitinib alone in previously treated patients with advanced non-small cell lung cancer. Clin Cancer Res 17: 1553-1560, 2011

73. Hong JY, Nam EM, Lee J, et al: Randomized double-blinded, placebo-controlled phase II trial of simvastatin and gemcitabine in advanced pancreatic cancer patients. Cancer Chemother Pharmacol 73: 125-130, 2014.

74. Limburg PJ, Mahoney MR, Ziegler KL, et al; Randomized phase II trial of sulindac, atorvastatin, and prebiotic dietary fiber for colorectal cancer chemoprevention. Cancer Prev Res 4: 259-269, 2011

75. Manoukian GE, Tannir NM, Jonasch E, Qiao W, Haygood TM and Tu SM: Pilot trial of bone-targeted therapy combining zoledronate with fluvastatin or atorvastatin for patients with metastatic renal cell carcinoma. Clin Genitourin Cancer 9: 81-88, 2011.
76. López-Aguilar E, Sepúlveda-Vildósola AC, Betanzos-Cabrera Y, et al: Phase II study of metronomic chemotherapy with thalidomide, carboplatin-vincristine-fluvastatin in the treatment of brain stem tumors in children. Arch Med Res 39: 655-662, 2008

77. Kornblau SM, Banker DE, Stirewalt D, et al: Blockade of adaptive defensive changes in cholesterol uptake and synthesis in AML by the addition of pravastatin to idarubicin + high-dose Ara-C: a phase 1 study. Blood 109: 2999-3006, 2007.

78. Graf H, Jüngst C, Straub G, et al: Chemoembolization combined with pravastatin improves survival in patients with hepatocellular carcinoma. Digestion 78: 34-38, 2008

79. Konings IR, van der Gaast A, van der Wijk LJ, de Jongh FE, Eskens FA and Sleijfer S: The addition of pravastatin to chemotherapy in advanced gastric carcinoma: a randomised phase II trial. Eur J Cancer 46: 3200-3204, 2010.

80. McKenna WG, Weiss MC, Bakanauskas VJ, et al: The role of the $\mathrm{H}$-ras oncogene in radiation resistance and metastasis. Int $\mathrm{J}$ Radiat Oncol Biol Phys 18: 849-859, 1990.

81. Miller AC, Kariko K, Myers CE, Clark EP and Samid D: Increased radioresistance of EJras-transformed human osteosarcoma cells and its modulation by lovastatin, an inhibitor of p21ras isoprenylation. Int J Cancer 53: 302-307, 1993.

82. Rozados VR, Hinrichsen LI, McDonnell J and Scharovsky OG: Lovastatin enhances in vitro radiation-induced apoptosis of rat B-cell lymphoma cells. J Exp Clin Cancer Res 24: 55-61, 2005.

83. Butt S, Butt T, Jirström K, et al: The target for statins, HMG-CoA reductase, is expressed in ductal carcinoma-in situ and may predict patient response to radiotherapy. Ann Surg Oncol 21: 2911-2919, 2014.

84. Mace AG, Gantt GA, Skacel M, Pai R, Hammel JP and Kalady MF: Statin therapy is associated with improved pathologic response to neoadjuvant chemoradiation in rectal cancer. Dis Colon Rectum 56: 1217-1227, 2013.

85. Werner M, Sacher J and Hohenegger M: Mutual amplification of apoptosis by statin-induced mitochondrial stress and doxorubicin toxicity in human rhabdomyosarcoma cells. Br J Pharmacol 143: 715-724, 2004

86. Holstein SA and Hohl RJ: Interaction of cytosine arabinoside and lovastatin in human leukemia cells. Leuk Res 25: 651-660, 2001.

87. Lishner M, Bar-Sef A, Elis A and Fabian I: Effect of simvastatin alone and in combination with cytosine arabinoside on the proliferation of myeloid leukemia cell lines. J Investig Med 49: 319-324, 2001.

88. Soma MR, Pagliarini P, Butti G, Paoletti R, Paoletti P and Fumagalli R: Simvastatin, an inhibitor of cholesterol biosynthesis, shows a synergistic effect with $N, N^{\prime}$-bis(2-chloroethyl)- $N$ nitrosourea and $\beta$-interferon on human glioma cells. Cancer Res 52: 4348-4355, 1992.

89. Wang W, Collie-Duguid E and Cassidy J: Cerivastatin enhances the cytotoxicity of 5 -fluorouracil on chemosensitive and resistant colorectal cancer cell lines. FEBS Lett 531: 415-420, 2002.

90. Katz MS, Minsky BD, Saltz LB, Riedel E, Chessin DB and Guillem JG: Association of statin use with a pathologic complete response to neoadjuvant chemoradiation for rectal cancer. Int $\mathrm{J}$ Radiat Oncol Biol Phys 62: 1363-1370, 2005

91. Brennan DJ, Brandstedt J, Rexhepaj E, et al: Tumour-specific HMG-CoAR is an independent predictor of recurrence free survival in epithelial ovarian cancer. BMC Cancer 10: 125, 2010.

92. Lipkin SM, Chao EC, Moreno V, et al: Genetic variation in 3-hydroxy-3-methylglutaryl CoA reductase modifies the chemopreventive activity of statins for colorectal cancer. Cancer Prev Res 3: 597-603, 2010

93. Yu CY, Theusch E, Lo K, et al: HNRNPA1 regulates $H M G C R$ alternative splicing and modulates cellular cholesterol metabolism. Hum Mol Genet 23: 319-332, 2014.

94. Sławińska-Brych A, Zdzisińska B and Kandefer-Szerszeń M: Fluvastatin inhibits growth and alters the malignant phenotype of the C6 glioma cell line. Pharmacol Rep 66: 121-129, 2014

95. Yongjun Y, Shuyun H, Lei C, Xiangrong C, Zhilin Y and Yiquan K: Atorvastatin suppresses glioma invasion and migration by reducing microglial MT1-MMP expression. J Neuroimmunol 260: 1-8, 2013

96. Crosbie J, Magnussen M, Dornbier R, Iannone A and Steele TA: Statins inhibit proliferation and cytotoxicity of a human leukemic natural killer cell line. Biomark Res 1: 33, 2013.

97. Al-Haidari AA, Syk I and Thorlacius H: HMG-CoA reductase regulates CCL17-induced colon cancer cell migration via geranylgeranylation and RhoA activation. Biochem Biophys Res Commun 446: 68-72, 2014. 
98. Ishikawa S, Hayashi H, Kinoshita K, et al: Statins inhibit tumor progression via an enhancer of zeste homolog 2-mediated epigenetic alteration in colorectal cancer. Int J Cancer 135: 2528-2536, 2014

99. Chang HL, Chen CY, Hsu YF, et al: Simvastatin induced HCT116 colorectal cancer cell apoptosis through p38MAPKp53-survivin signaling cascade. Biochim Biophys Acta 1830: 4053-4064, 2013

100. Rentala S, Chintala R, Guda M, Chintala M, Komarraju AL and Mangamoori LN: Atorvastatin inhibited Rho-associated kinase 1 (ROCK1) and focal adhesion kinase (FAK) mediated adhesion and differentiation of $\mathrm{CD} 133^{+} \mathrm{CD} 44^{+}$prostate cancer stem cells. Biochem Biophys Res Commun 441: 586-592, 2013.

101. Peng X, Li W, Yuan L, Mehta RG, Kopelovich L and McCormick DL: Inhibition of proliferation and induction of autophagy by atorvastatin in PC3 prostate cancer cells correlate with downregulation of Bcl2 and upregulation of miR-182 and p21. PLoS One 8: e70442, 2013.

102. Al-Husein B, Goc A and Somanath PR: Suppression of interactions between prostate tumor cell-surface integrin and endothelial ICAM-1 by simvastatin inhibits micrometastasis. J Cell Physiol 228: 2139-2148, 2013.

103. Fang Z, Tang Y, Fang J, et al: Simvastatin inhibits renal cancer cell growth and metastasis via AKT/mTOR, ERK and JAK2/STAT3 pathway. PLoS One 8: e62823, 2013.

104. Islam M, Sharma S, Kumar B and Teknos TN: Atorvastatin inhibits RhoC function and limits head and neck cancer metastasis. Oral Oncol 49: 778-786, 2013.

105. Yu X, Pan Y, Ma H and Li W: Simvastatin inhibits proliferation and induces apoptosis in human lung cancer cells. Oncol Res 20: 351-357, 2013.

106. Pelaia G, Gallelli L, Renda T, et al: Effects of statins and farnesyl transferase inhibitors on ERK phosphorylation, apoptosis and cell viability in non-small lung cancer cells. Cell Prolif 45 $557-565,2012$

107. Chen J, Liu B, Yuan J, et al: Atorvastatin reduces vascular endothelial growth factor (VEGF) expression in human non-small cell lung carcinomas (NSCLCs) via inhibition of reactive oxygen species (ROS) production. Mol Oncol 6: 62-72, 2012.

108. Guterres FA, Martinez GR, Rocha ME and Winnischofer SM: Simvastatin rises reactive oxygen species levels and induces senescence in human melanoma cells by activation of p53/p21 pathway. Exp Cell Res 319: 2977-2988, 2013.

109. Pich C, Teiti I, Rochaix P, et al: Statins reduce melanoma development and metastasis through MICA overexpression. Front Immunol 4: 62, 2013

110. Gopalan A, Yu W, Sanders BG and Kline K: Simvastatin inhibition of mevalonate pathway induces apoptosis in human breast cancer cells via activation of JNK/CHOP/DR5 signaling pathway. Cancer Lett 329: 9-16, 2013

111. Park YH, Jung HH, Ahn JS and Im YH: Statin induces inhibition of triple negative breast cancer (TNBC) cells via PI3K pathway. Biochem Biophys Res Commun 439: 275-279, 2013.

112. Zhao Z, Cao X, Pan Y, Sha S, Zhao T and Zhang T: Simvastatin downregulates HER2 via upregulation of PEA3 to induce cell death in HER2-positive breast cancer cells. Oncol Res 20 $187-195,2012$

113. Qi XF, Zheng L, Lee KJ, et al: HMG-CoA reductase inhibitors induce apoptosis of lymphoma cells by promoting ROS generation and regulating Akt, Erk and p38 signals via suppression of mevalonate pathway. Cell Death Dis 4: e518, 2013.

114. Zeng M, Gu WY, Jiang TX, et al: Effects of simvastatin on PI3K/AKT signaling pathway in human acute monocytic leukemia cell line SHI-1. Zhongguo Shi Yan Xue Ye Xue Za Zhi 20: 268-272, 2012 (In Chinese).

115. Yang SS, Li R, Qu X, Fang W and Quan Z: Atorvastatin decreases Toll-like receptor 4 expression and downstream signaling in human monocytic leukemia cells. Cell Immunol 279: 96-102, 2012.
116. Shi J, Zhu J, Zhao H, Zhong C, Xu Z and Yao F: Mevalonate pathway is a therapeutic target in esophageal squamous cell carcinoma. Tumour Biol 34: 429-435, 2013.

117. Ma L, Niknejad N, Gorn-Hondermann I, Dayekh K and Dimitroulakos J: Lovastatin induces multiple stress pathways including LKB1/AMPK activation that regulate its cytotoxic effects in squamous cell carcinoma cells. PLoS One 7: e46055, 2012.

118. Tu YS, Kang XL, Zhou JG, Lv XF, Tang YB and Guan YY: Involvement of Chk1-Cdc25A-cyclin A/CDK2 pathway in simvastatin induced $\mathrm{S}$-phase cell cycle arrest and apoptosis in multiple myeloma cells. Eur J Pharmacol 670: 356-364, 2011.

119. Araki M, Maeda M and Motojima K: Hydrophobic statins induce autophagy and cell death in human rhabdomyosarcoma cells by depleting geranylgeranyl diphosphate. Eur J Pharmacol 674 95-103, 2012.

120. Liu H, Wang Z, Li Y, Li W and Chen Y: Simvastatin prevents proliferation and bone metastases of lung adenocarcinoma in vitro and in vivo. Neoplasma 60: 240-246, 2013.

121. Liao J, Chung YT, Yang AL, et al: Atorvastatin inhibits pancreatic carcinogenesis and increases survival in $L S L-\mathrm{Kras}^{G 12 D}-L S L$ Trp53 ${ }^{R 172 H}-P d x 1-C r e$ mice. Mol Carcinog 52: 739-750, 2013.

122. Vitols S, Angelin B and Juliusson G: Simvastatin impairs mitogen-induced proliferation of malignant B-lymphocytes from humans - in vitro and in vivo studies. Lipids 32: 255-262, 1997.

123. Higgins MJ, Prowell TM, Blackford AL, et al: A short-term biomarker modulation study of simvastatin in women at increased risk of a new breast cancer. Breast Cancer Res Treat 131: 915-924, 2012

124. Bansal D, Undela K, D'Cruz S and Schifano F: Statin use and risk of prostate cancer: a meta-analysis of observational studies. PLoS One 7: e46691, 2012.

125. Park HS, Schoenfeld JD, Mailhot RB, et al: Statins and prostate cancer recurrence following radical prostatectomy or radiotherapy: a systematic review and meta-analysis. Ann Oncol 24 $1427-1434,2013$

126. Singh PP and Singh S: Statins are associated with reduced risk of gastric cancer: a systematic review and meta-analysis. Ann Oncol 24: 1721-1730, 2013

127. van der Spek E, Bloem AC, Sinnige HA and Lokhorst HM: High dose simvastatin does not reverse resistance to vincristine, adriamycin, and dexamethasone (VAD) in myeloma. Haematologica 92: e130-e131, 2007.

128. Han JY, Lim KY, Yu SY, Yun T, Kim HT and Lee JS: A phase 2 study of irinotecan, cisplatin, and simvastatin for untreated extensive-disease small cell lung cancer. Cancer 117: 2178-2185, 2011.

129. Kim WS, Kim MM, Choi HJ et al: Phase II study of high-dose lovastatin in patients with advanced gastric adenocarcinoma. Invest New Drugs 19: 81-83, 2001.

130. Lazzeroni M, Guerrieri-Gonzaga A, Serrano D, et al: Breast ductal lavage for biomarker assessment in high risk women: rationale, design and methodology of a randomized phase II clinical trial with nimesulide, simvastatin and placebo. BMC Cancer 12: 575, 2012.

131. Kawata S, Yamasaki E, Nagase T, et al: Effect of pravastatin on survival in patients with advanced hepatocellular carcinoma. A randomized controlled trial. Br J Cancer 84: 886-891, 2001.

132. Lersch C, Schmelz R, Erdmann J, et al: Treatment of HCC with pravastatin, octreotide, or gemcitabine - a critical evaluation. Hepatogastroenterology 51: 1099-1103, 2004.

133. Knox JJ, Siu LL, Chen E, et al: A Phase I trial of prolonged administration of lovastatin in patients with recurrent or metastatic squamous cell carcinoma of the head and neck or of the cervix. Eur J Cancer 41: 523-530, 2005. 